\title{
Cardioprotection Techniques: Preconditioning, Postconditioning and Remote Con-ditioning (Basic Science)
}

\author{
Derek J. Hausenloy* \\ The Hatter Cardiovascular Institute, University College London Hospital \& Medical School, 67 Chenies Mews, London, WC1E 6HX, \\ $U K$
}

\begin{abstract}
Ischemic heart disease (IHD) is the leading cause of death and disability worldwide. The major pathological consequences of IHD arise from the detrimental effects of acute ischemia-reperfusion injury (IRI) on the myocardium. Therefore, in order to improve clinical outcomes in patients with IHD, novel therapeutic strategies are required to protect the myocardium from acute IRI and preserve cardiac function (cardioprotection). In this regard, endogenous cardioprotective strategies such as ischemic preconditioning (IPC), ischemic postconditioning (IPost) and remote ischemic conditioning (RIC) may provide novel approaches for protecting the heart in clinical settings in which the patient experiences acute myocardial IRI. In this review article, we provide an overview of these endogenous cardioprotective strategies with respect to the pre-clinical experimental literature, exploring their major characteristics and underlying signaling mechanisms. The application of these therapeutic strategies in the clinical setting for potential patient benefit is reviewed in another article in this special issue.
\end{abstract}

Keywords: Ischemic preconditioning, ischemic postconditioning, remote ischemic conditioning, cardioprotection, ischemia-reperfusion injury.

\section{INTRODUCTION}

".....we could exploit ischemia to protect the heart from ischemic injury." Murry et al 1986 [1].

Ischemic heart disease (IHD) is the leading cause of death and disability worldwide. Despite optimal therapy, the morbidity and mortality from IHD remain significant. As such, novel therapeutic strategies are required to protect the heart from the detrimental effects of acute ischemia-reperfusion injury (IRI), in order to reduce myocardial injury, preserve cardiac function and improve clinical outcomes in patients with IHD.

Over 25 years ago, Murry and co-workers [1] first introduced the possibility of harnessing the heart's own ability to protect itself from acute lethal IRI by preconditioning it with brief non-lethal episodes of ischemia and reperfusion, an endogenous cardioprotective phenomenon which was termed ischemic preconditioning (IPC). In that landmark experimental study, four-5 min cycles of alternating left anterior descending (LAD) coronary artery occlusion and reflow applied immediately prior to a 90 min LAD occlusion and 3 day reperfusion period, reduced myocardial infarct (MI) size in the canine heart to $25 \%$ of that observed in untreated control hearts. The inspiration for undertaking this seminal study was based on the results of experimental studies which had unexpectedly found that repeated bouts of myocardial ischemia and reperfusion did not cause a cumulative detrimental effect on myocardial ATP content, cell death and myocardial function $[2,3]$.

IPC remains one of the most powerful therapeutic strategies for reducing MI size and has become a ubiquitous phenomenon, protecting every species it has been tested in including man. Despite intensive investigation and the publication of nearly 7,000 studies on PubMed, the on-going challenge has been to elucidate the mechanistic pathways underlying IPC. Over the years the concept of IPC has evolved to include ischemic postconditioning (IPost) and remote ischemic conditioning (RIC), therapeutic strategies which can be collectively termed ischemic conditioning. These advances have greatly facilitated the translation of ischemic conditioning into

\footnotetext{
*Address correspondence to this author at The Hatter Cardiovascular Institute, University College London Hospital \& Medical School, 67 Chenies Mews, London, WC1E 6HX, UK; Tel: +44 (203) 447 9894;

Fax: +44 (203) 447 9505; E-mail: d.hausenloy@ucl.ac.uk
}

the clinical settings of acute IRI. The clinical application of ischemic conditioning is discussed in another article in this special issue. In this review article, an overview will be provided of these 3 forms of ischemic conditioning, with respect to the pre-clinical experimental literature exploring their major characteristics and underlying signalling mechanisms. It would be impossible for a single review article to provide a comprehensive account of these individual endogenous cardioprotective phenomena and for this the reader is referred to the following review articles [4-7].

\section{HOW THE CONCEPT OF IPC HAS EVOLVED OVER THE YEARS}

The concept of IPC has evolved over the years since its initial discovery in 1986 to now include remote ischemic conditioning (RIC) and ischemic postconditioning (IPost). The first major development took place in 1993 by Przyklenk et al [8] who found that applying an IPC protocol in one coronary vascular territory could actually protect the myocardium in a different coronary vascular territory from a subsequent lethal episode of acute myocardial IRI. In this landmark experimental study undertaken in canine hearts, IPC in the circumflex artery (four-5 min alternating cycles of occlusion and reflow), immediately prior to a $60 \mathrm{~min}$ LAD occlusion and 3 day reperfusion period, reduced MI size to $38 \%$ of that observed in untreated control hearts [8]. The idea of undertaking this experiment was based on the findings of a study by the same research group in isolated rat hearts, in which it was demonstrated that MI size expressed as a percentage of the area-at-risk actually increased in IPC-treated hearts whereas in control hearts, MI size did not increase [9]. This led the authors to propose that IPC might somehow produce a diffusible protective factor in remote non-ischemic myocardium [9]. This intramyocardial preconditioning effect between two different but adjacent coronary vascular beds was further developed in an experimental study in 1996, demonstrating that the IPC stimulus could actually be applied to an organ away from the heart. Gho et al [10] demonstrated that applying $15 \mathrm{~min}$ of anterior mesenteric artery occlusion followed by $15 \mathrm{~min}$ reflow to induce a brief period of episode of intestinal ischemia and reperfusion immediately prior to $60 \mathrm{~min}$ coronary artery occlusion and $180 \mathrm{~min}$ reflow reduced subsequent myocardial infarct size by $28 \%$. This phenomenon has been termed remote ischemic preconditioning (RIPC), and subsequent studies have demonstrated that the precon- 
ditioning stimulus can be applied in any organ or tissue to protect any other organ or tissue from a sustained lethal episode of acute IRI- termed inter-organ preconditioning [7]. Crucially, the remote preconditioning stimulus has been shown to be effective if applied prior to (RIPC) [10], after the onset of (remote ischemic preconditioning) [11] and even at the onset of myocardial reperfusion (remote ischemic postconditioning) [12]. Furthermore, the ability to remotely precondition the upper or lower limb to protect the heart from acute IRI has greatly facilitated the translation of remote ischemic preconditioning into the clinical setting of cardiac surgery, acute myocardial infarction and coronary angioplasty [13-16].

The next major development occurred soon after the first description of RIPC, with the discovery in 1993 by Kuzuya et al [17] that IPC actually induced two distinct windows of cardioprotection. These authors demonstrated in the canine heart that following a standard IPC stimulus, MI size reduction was observed immediately but was lost 6 or 12 hours later and then re-appeared again at 24 hours and lasted until 72 hours [17]. This delayed effect of IPC has been termed the second window of protection or delayed or late preconditioning [18].

In 2003, Zhao et al [19] found that by simply interrupting myocardial reperfusion with several short-lived episodes of myocardial ischemia could reduce MI size to a level comparable to IPC. These authors demonstrated in canine hearts that following a $60 \mathrm{~min}$ of coronary artery occlusion, by allowing reflow for 30 seconds and then re-occluding the coronary artery for 30 seconds a cycle which was repeated a total of 3 times, reduced MI size when compared to hearts which received uninterrupted reperfusion [19]. This phenomenon, which has been termed ischemic postconditioning (IPost) provides a cardioprotective therapeutic strategy which can be applied at the onset of myocardial reperfusion, thereby allowing its rapid translation into the clinical setting in patients presenting with an acute myocardial infarction [20] and in patients undergoing cardiac surgery [21]. The elucidation of the mechanisms underlying these different forms of ischemic conditioning has identified novel targets for cardioprotection amenable to pharmacological manipulation (so-called pharmacological conditioning).

\section{ISCHEMIC PRECONDITIONING}

\subsection{The IPC Stimulus}

In the original study by Murry et al [1], four-5 min cycles of myocardial ischemia and reperfusion were chosen to precondition the canine heart against myocardial infarction. This treatment protocol was chosen by the authors as longer periods of myocardial ischemia (such as 10 or $15 \mathrm{~min}$ ) resulted in arrhythmias and increased mortality [1]. The stated reason for using four cycles was to increase the formation and wash-out of ischemic catabolites [1]. The 5 min reperfusion period was chosen to be long enough to wash-out lactate and re-accumulate high-energy phosphates [1]. A wide variety of stimuli have been shown to induce a preconditioning-like effect in terms of cardioprotection such as heat stress, hypothermia, exercise, pacing, myocardial stretch and so forth.

A standard IPC stimulus induces 2 phases of cardioprotection: the first phase (termed classical preconditioning or the first window of protection) begins immediately following the IPC stimulus and lasts for 2-3 hours, after which the cardioprotective effect wanes and disappears, and a second phase (termed delayed or late preconditioning or the second window of cardioprotection) re-appearing 12-24 hours later and lasting up to 72 hours [18].

\subsection{The Signaling Pathways Underlying IPC}

The intracellular signalling pathways underlying ischemic conditioning in the heart are numerous and remarkably complex and as such, they cannot be comprehensively reviewed in a single article. For IPC, the current paradigm suggests that the cardiomyocyte generates autacoids (such as adenosine, bradykinin, endothelin, opioids) in response to the IPC stimulus which bind to their respec- tive G-protein coupled receptors and activate a number of signalling pathways, many of which appear to converge on the mitochondria (see (Fig. 1) for a simplified overview). In IPC, the signal transduction pathway can be conceptually classified into triggers (these are components of the signaling pathway which mainly act before the index ischemic episode and activate downstream signaling mediators) or mediators and end-effectors (these are components of the signaling pathway which act during the index ischemic episode or at the time of reperfusion and mediate the protective effect). However, this separation is not rigid as certain signaling components have been demonstrated to act as both triggers and mediators/effectors.

\subsubsection{Triggers of IPC}

In 1991, Liu et al [22] first implicated the adenosine A1 receptor as a trigger of IPC, by demonstrating that it could be blocked by the non-specific adenosine receptor blocker, 8-sulfophenyltheophylline (8-SPT), and that the intracoronary administration of either adenosine or an adenosine A1 receptor agonist could reduce MI size. These important findings demonstrated that IPC was a receptor-mediated phenomenon and suggested that the infarctlimiting effects of IPC could be mimicked by a pharmacological agent [22]. Other GPCR ligands have been implicated as triggers of IPC such as bradykinin [23, 24], opioids [25], acetylcholine [26], catecholamines [27], angiotensin II [28], and endothelin-1 [29]. The IPC triggers are highly redundant with multiple cycles of IPC able to overcome the effect of antagonism at a single receptor [24]. The simultaneous activation of these GPCRs during the IPC stimulus suggested that the cardioprotective signal probably converges on a single downstream mediator, protein kinase $\mathrm{C}$ (PKC), which mediates the memory effect of IPC. Other triggers of IPC, which are dealt with in later sections, include the $\mathrm{MitoK}_{\mathrm{ATP}}$ channel, reactive oxygen species (ROS) and nitric oxide.

\subsubsection{Mediators of IPC}

The downstream mediators of IPC are mainly protein kinases such as PKC, tyrosine kinase, Akt, and the mitogen activated protein kinases (MAPK) which are activated by the triggers of IPC. Experimental studies by Ytrehus et al in 1994 [30] showed that IPC could be blocked a non-specific antagonist of PKC and reproduced by $\mathrm{PKC}$ analogues. Although there are some differences with species, IPC has been reported to activate the PKC- $\varepsilon$ isoform as a mediator of cardioprotection, whereas it has shown to inhibit the activation of the PKC- $\delta$ isoform, which has been reported to have detrimental effects in the setting of IRI. It has been suggested that the PKC- $\varepsilon$ isoform may play a key role in the mitochondria. In 1996, Maulik et al [31] were the first to demonstrate that genistein, a tyrosine kinase antagonist could block IPC in rat hearts. Receptor tyrosine kinases may act as IPC triggers by activating PKC and cytosolic tyrosine kinases may act as IPC mediators by acting either downstream or in parallel with PKC [32].

Experimental studies have implicated signaling through the phosphatidyl inositol 3-OH kinase (PI3K)-Akt cascade during the preconditioning phase before the index ischemic episode [33] and at the time of myocardial reperfusion as part of the Reperfusion Injury Salvage Kinase (RISK) pathway [34]. In IPC Tong and colleagues [33] were the first to demonstrate that IPC activates the PI3K-Akt kinase cascade prior to the index ischaemic episode, and that the PI3K inhibitor Wortmannin could abolish IPC. We showed that IPC could activate Akt at the time of myocardial reperfusion and that pharmacologically inhibiting PI3K at this time could block IPC protection, suggesting that IPC could modify signalling events happening at the time of myocardial reperfusion [34]. Solenkova et al [35] extended these findings by demonstrating that the IPC induced activation of Akt could be abrogated by 8-SPT (an adenosine receptor antagonist), suggesting that endogenous adenosine activated Akt in preconditioned hearts. 


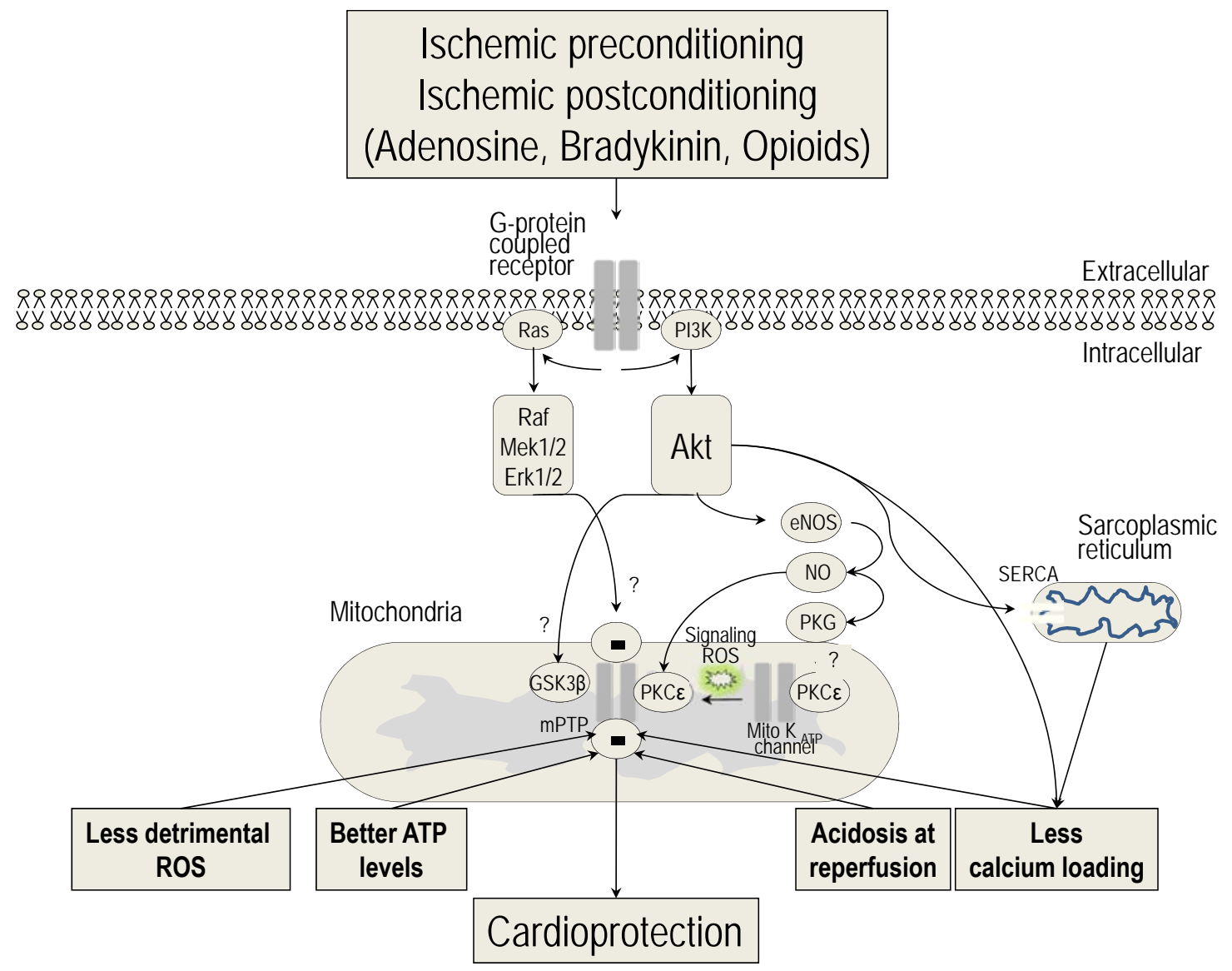

Fig. (1). Signaling pathways linking IPC and IPost to the mPTP. This scheme provides a simplified overview of two of the major signaling pathways implicated in both IPC and IPost which link the cell-surface receptor to the mPTP. Of course many other signalling pathways have been implicated in both IPC and IPost but for the purposes of clarity these have not been included in this scheme. IPC and IPost are both seen to activate cell surface receptor, which then recruit a number of signal transduction pathways including the PI3K-Akt and MEK1/2-Erk1/2 pathways which terminate on the mitochondria with the activation of the MitoK $\mathrm{ATP}_{\mathrm{A}}$ channel and the inhibition of the mPTP. (Figure adapted from [150]).

Whether Erk1/2 MAPK contributes to cardio-protection associated with classical preconditioning is unclear with studies demonstrating that it is activated prior to the index ischaemic period [3639], but only some of these studies show these MAPK's contributing to IPC-induced protection [36, 37]. In contrast there are studies reporting no change in Erk1/2 activity in the setting of IPC [40, 41]. A study suggests that diazoxide-induced mitochondrial ROS release may activate Erk1/2 [42]. This is interesting given the findings of Baines and colleagues demonstrating that PKC- $\varepsilon$ modules can form complexes with Erk1/2-BAD, p38 and JNK at the mitochondria [43]. In this scenario, PKC- $\varepsilon$ appeared to phosphorylate both Erk1/2 and p38 but down-regulate JNK [43]. Erk1/2 can mediate cellular protection by phosphorylating recruiting several anti-apoptotic mechanisms.

The role of p38 MAPK in the setting of cardioprotection has been surrounded by controversy and has been the topic of several reviews [44, 45]. There is general agreement that ischemiareperfusion activates p38 MAPK [46], but the studies investigating the role of p38 MAPK in cardioprotection have attracted much controversy. Experimental Studies suggest that IPC can activate [47-49] or reduce [39, 50, 51] p38 MAPK during the sustained ischemic episode. The generally accepted view is that IPC transiently activates p38 MAPK during the preconditioning phase [5254], and reduces the p38 MAPK activation that occurs during the sustained ischemic phase [50,54-56]. Studies have suggested that the p38 $\alpha$-isoform may mediate cell death and the p38 $\beta$-isoform may contribute to cell survival [57]. In line with this, studies have suggested that it is the $\mathrm{p} 38 \alpha$ isoform which is increased during ischemia $[39,52]$, and that hypoxic preconditioning protects myocytes by reducing the activation of this isoform during hypoxia [39]. Conversely, Schulz and co-workers [58] found p38 $\beta$ MAPK activity to be increased in preconditioned swine hearts.

Experimental studies have demonstrated JNK activation in the setting of ischemia-reperfusion [40, 46, 52, 59]. The role of JNK in the setting of IPC has been controversial with studies, suggesting both a protective and detrimental aspect to JNK activation. Studies have demonstrated JNK activation in response to a preconditioning stimulus $[40,52,60,61]$ and that JNK mediates the protective effect of IPC [53]. Other reports have found JNK activation in response to a preconditioning stimulus but have failed to find it contributing to protection [62]. Yet other studies have failed to find activation of JNK in the setting of IPC [63]. Unfortunately, a recently published study examining the effect of JNK $1 / 2$ transgenic knock-outs has only served to complicate matters further [64]. In this study transgenic JNK knockout mice were found to be protected in vivo against myocardial ischemia-reperfusion injury. However, transgenic mice with over-active MKK7, the MAPK kinase upstream of JNK1/2 also paradoxically displayed resistance to myocardial ischemia-reperfusion injury, as evidenced by a reduced infarct size [64].

\subsubsection{Effectors of IPC}

A number of different effectors have been proposed over the years but most evidence has implicated mitochondria as the endeffectors of IPC. 


\subsection{IPC and Mitochondria}

The initial experimental studies to implicate mitochondria in the signaling pathway of IPC were designed to investigate the mechanism for the preserved myocardial ATP content in preconditioned hearts as originally proposed by Murry et al [1]. Over the years, the role of mitochondria in IPC has expanded them being potential trigger and effectors of cardioprotection. It appears that any stimulus which mildly stresses mitochondrial function is capable of initiating IPC. This mitochondrial stress then sets into place, through the activation of various pro-survival signaling pathways, a mitochondrial phenotype which is protected against a sustained lethal insult of IRI.

\subsection{IPC and Myocardial Energy Production}

In the initial IPC studies undertaken by Murry et al In 1990 [1, 65] first proposed that IPC may protect the heart by reducing myocardial energy demand during myocardial ischemia thereby preventing cell death by preserving myocardial ATP content and/or reducing catabolite accumulation. This proposal has been supported by a number of experimental studies reporting preserved mitochondrial function and maintained levels of high-energy phosphates [66]. The opening of the MitoKATP channel has been demonstrated to increase ATP synthesis [67], preserve mitochondrial energy production [68], decrease ATP hydrolysis [69] and improve energy transfer at reperfusion [69].

\subsection{IPC and $\mathrm{pH}$}

During a sustained lethal episode of myocardial ischemia, the reduction in oxygen favors anaerobic glycolysis leading to ATP hydrolysis and the accumulation of lactic acid and a fall in the intracellular $\mathrm{pH}$ to 6.0. The increase in intracellular $\mathrm{H}^{+}$activates the $\mathrm{Na}^{+}-\mathrm{H}^{+}$exchanger which extrudes $\mathrm{H}^{+}$ions in exchange for $\mathrm{Na}^{+}$ions resulting in intracellular $\mathrm{Na}^{+}$which in turn causes the $\mathrm{Na}^{+}-\mathrm{Ca}^{2+}$ exchanger to work in reverse mode extruding $\mathrm{Na}^{+}$ions in exchange for $\mathrm{Ca}^{2+}$ ions the end result of which is intracellular $\mathrm{Ca}^{2+}$ overload. On reperfusing the ischemic myocardium the wash-out of lactate and the re-activation of ion pumps result in the rapid restoration of intracellular $\mathrm{pH}$ to pre-ischemic physiological levels of $\mathrm{pH}$ 7.4.

In 1990, Murry et al [65] first proposed that IPC may protect the heart by increasing glycogen depletion and reducing the rate of anerobic glycolysis during myocardial ischemia. Initial experimental studies did find glycogen depletion, decreased myocardial lactate, and less intracellular acidosis during myocardial ischemia in IPC-treated hearts $[65,70,71]$, the expected result of which would be reduced activation of the $\mathrm{Na}^{+}-\mathrm{H}^{+}$and $\mathrm{Na}^{+}-\mathrm{Ca}^{2+}$ exchangers and less intracellular $\mathrm{Ca}^{2+}$ accumulation [72]. However, subsequent experimental studies have dissociated both glycogen depletion, decreased lactate accumulation and less intracellular acidosis with IPC cardioprotection [73, 74].

Interestingly, the rapid restoration of intracellular physiological $\mathrm{pH}$ at the onset of myocardial reperfusion did not appear to be affected by IPC [75], a finding which differs from IPost, which has been shown to delay the restoration of intracellular physiological $\mathrm{pH}$ within the heart, as a cardioprotective mechanism linked to inhibition of mPTP opening [76-78].

\subsection{IPC and Calcium}

Intracellular and mitochondrial calcium overload during myocardial ischemia and reperfusion can cause cardiomyocyte death by a number of different mechanisms including mPTP opening and cardiomyocyte hypercontracture [79, 80]. IPC has been reported to protect the heart by reducing intracellular calcium and mitochondrial calcium accumulation. The underlying mechanism for this beneficial effect of IPC on calcium handling is unclear, and has been attributed to opening of the sarcolemmal $\mathrm{K}_{\mathrm{ATP}}$ channel (with action potential duration shortening) [81], opening of the MitoK $_{\mathrm{ATP}}$ channel (with partial mitochondrial membrane depolarization and less mitochondrial calcium accumulation) [82-90], and reduced intracellular acidosis during myocardial ischemia (see previous section) [72].

\subsection{IPC and ROS}

Reactive oxygen species (ROS) appear to play a dual role in the setting of IPC. On the one hand, the production of mitochondrial ROS (such as superoxide anion, hydrogen peroxide and hydroxyl radical) from the re-energization of the mitochondrial electron transport chain in the first few minutes of myocardial reperfusion mediates cardiomyocyte death by inducing mitochondrial permeability transition pore (mPTP) opening and causing cell membrane damage by lipid peroxidation. On the other hand the generation of small amounts of signaling ROS prior to the index episode of myocardial ischemia in response to a standard IPC stimulus is also required to mediate cardioprotection through the activation of prosurvival protein kinases such as PKC [91], Erk1/2 [42], and p38 MAPK [92].

\subsubsection{IPC Attenuates Mitochondrial Production of ROS at Reper- fusion}

In 1994, Tosaki et al [28] first reported that IPC attenuated the production of ROS (detected indirectly by levels of malondialdehyde) at the onset of myocardial reperfusion in isolated perfused rat hearts. Using Lucigenin-enhanced chemiluminescence to directly measure levels of ROS in the isolated perfused rat heart, Crestanello et al $[93,94]$ found that IPC generated a burst of ROS immediately following the IPC stimulus and decreased the production of ROS in the first 4 min of myocardial reperfusion when compared to control hearts. These findings have been confirmed in a number of subsequent experimental studies [95-99]. However, the actual mechanism through which IPC attenuates mitochondrial production of ROS at the onset of myocardial reperfusion remains unclear. It has been suggested that IPC may prevent mitochondrial respiratory impairment during myocardial ischemia thereby resulting in less mitochondrial ROS production at time of myocardial reperfusion. Another hypothesis is that IPC somehow prevents the following process: during myocardial ischemia, outer mitochondrial membrane permeabilization allows the release of mitochondrial cytochrome $\mathrm{C}$, the effect of which is increased mitochondrial ROS production [100].

Whether IPC can affect ROS production during myocardial ischemia is unclear. Experimental studies have demonstrated that minimal amounts of ROS were produced during myocardial ischemia and IPC had no effect on this [94, 95], whereas one experimental study has reported that IPC reduced the production of ROS in the last $10 \mathrm{~min}$ of myocardial ischemia in the isolated guinea pig heart [101]. In the latter study it was suggested that the ROS generated in the terminal phase of ischemia may somehow prime the heart for injury during myocardial reperfusion [101].

\subsubsection{IPC Generates Signaling ROS Prior to Myocardial Ische-} mia

When present in low concentrations, reactive oxygen species (ROS), can modify cellular activities and participate in intracellular signalling [102]. In 1988, Murry et al [103] first demonstrated that antioxidants could abolish the protective effect of IPC, implicating for the first time a potential role for signalling ROS as a mediator of IPC, a finding which was later confirmed by several subsequent experimental studies [91, 104, 105]. In 1996, Crestanello et al [94] demonstrated that IPC generated a burst of ROS, a finding which has been confirmed in several studies [101, 106]. In 1997, Tritto et al [107] were the first to demonstrate directly that a low dose of ROS could mimic IPC-induced protection. A year later, Vanden Hoek et al [106] demonstrated using chick neonatal cardiomyocytes that the source of the preconditioning signaling ROS (mainly $\mathrm{H}_{2} \mathrm{O}_{2}$ ) was complex III of the mitochondrial electron transport chain. The mechanism through which IPC generates a burst of mitochondrial 
signalling ROS has been attributed to the opening of the mitochondrial ATP-sensitive potassium $\left(\right.$ MitoK $_{\mathrm{ATP}}$ ) channel (see the next section)

\subsection{IPC and the Mitochondrial $K_{\mathrm{ATP}}$ Channel}

The role of the $\mathrm{K}_{\mathrm{ATP}}$ channel in IPC has had an interesting and often controversial history. In 1983, Noma [108] first identified a sarcolemmal ATP-sensitive potassium $\left(\mathrm{K}_{\mathrm{ATP}}\right)$ channel in isolated guinea pig cardiomyocytes, the opening of which in response to hypoxia or ischemia could protect the heart against IRI by shortening the action potential duration thereby reducing intracellular $\mathrm{Ca}^{2+}$ loading. In 1992, Gross et al [109, 110] were the first to implicate the sarcolemmal $\mathrm{K}_{\mathrm{ATP}}$ channel as a mediator of IPC, by demonstrating that IPC cardioprotection could be abolished by the sarcolemmal $\mathrm{K}_{\mathrm{ATP}}$ channel blockers glibenclamide or 5-hydroxydecanoic acid (5-HD). Mice lacking the Kir6.2 component of the sarcolemmal $\mathrm{K}_{\mathrm{ATP}}$ channel blockers have been reported to be resistant to IPC [111].

Following the discovery in 1991 of a $\mathrm{K}_{\mathrm{ATP}}$ channel in the inner mitochondrial membrane [112], Garlid et al in 1997 [113] and Liu et al in 2008 [114] demonstrated a role for the MitoK $\mathrm{ATP}_{\mathrm{A}}$ channel as a trigger of IPC. The current paradigm suggests that the opening of the MitoK $_{\mathrm{ATP}}$ channel in response to the IPC stimulus is required to generate the mitochondrial signalling ROS required for the activation of downstream mediators of IPC cardioprotection such as PKC [115-119]. The mechanism through which MitoK $_{\text {ATP }}$ channel activation generates ROS is unclear but the current proposition is that the opening of the mitochondrial $\mathrm{K}_{\mathrm{ATP}}$ channel causes $\mathrm{K}^{+}$influx into the mitochondrial matrix coupled with $\mathrm{H}^{+}$efflux out of the mitochondria. The increase in matrix $\mathrm{pH}$ is accompanied by the influx of anions such as $\mathrm{P}_{\mathrm{i}}$, but because of the relatively low cytosolic concentration of $\mathrm{P}_{\mathrm{i}}$, the net effect of $\mathrm{K}^{+}$influx is matrix alkanization, which in turn increases mitochondrial ROS production from complex I [120-122].

However, the role of the MitoK $\mathrm{K}_{\mathrm{ATP}}$ channel as a trigger of IPC cardioprotection has been surrounded by controversy due to two main factors: (i) much of the evidence supporting the role of this channel in IPC is based upon the use of pharmacological activator and inhibitors of the Mito $_{\text {ATP }}$ channel such as diazoxide and 5$\mathrm{HD}$, respectively, agents which has been reported to have nonspecific effects on mitochondrial function [123]; and (ii) although the molecular structure of the sarcolemmal $\mathrm{K}_{\mathrm{ATP}}$ channel is known to consist of an octomeric complex containing four Kir6.2 (an inwardly-rectifying $\mathrm{K}^{+}$channel) subunits and four SUR2 (sulphonylurea receptor) subunits $[124,125]$, the molecular composition of the MitoK $_{\text {ATP }}$ channel remains unknown. The situation has been further complicated with the discovery of a $\mathrm{Ca}^{2+}$-activated $\mathrm{K}^{+}$channel in the inner mitochondrial membrane that can mediate protection against IRI [126].

\subsection{IPC and Nitric Oxide}

Whether the signalling molecule nitric oxide (NO) is a trigger for classical IPC was initially controversial [127-130]. However, in the current paradigm for IPC signaling, NO is a critical mediator in the IPC signalling pathways. The evidence for NO and iNOS in the setting of delayed IPC or SWOP is more persuasive [131, 132].

\subsection{IPC and the mPTP}

The MPTP is a non-selective channel of the inner mitochondrial membrane which forms and opens in the first few minutes of myocardial reperfusion in response to calcium, oxidative stress, phosphate and ADP [133]. Its opening collapses the mitochondrial membrane potential, halting mitochondrial oxidative phosphorylation resulting in ATP depletion and cell death. Furthermore, its opening allows water and solutes to equilibriate with the mitochondrial matrix leading to mitochondrial swelling and rupture of the outer mitochondrial membrane and the translocation of pro- apoptotic factors such as cytochrome $\mathrm{C}$ into the cytosol inducing apoptosis. Preventing its opening at the time of myocardial reperfusion is a critical target for cardioprotection. In this regard, Crompton's research laboratory made the crucial discovery that the opening of the MPTP induced by calcium, phosphate and oxidative stress could be pharmacologically inhibited by the immunosuppressant drug, cyclosporine-A (CsA), which targets cyclophilin D, regulatory component of the mPTP [134-136]. Since then we and others have demonstrated that pharmacologically inhibiting mPTP opening at the onset of reperfusion can reduce MI size [137-139], a therapeutic strategy which has been applied in the clinical setting [140]. Importantly, mice deficient in cyclophilin-D sustained smaller MI [135, 136] and cerebral infarcts [141], underscoring the importance of the MPTP as a mediator of IRI in both the heart and brain.

The first study to suggest that the MPTP may be a potential target for calcium-induced preconditioning protection was by Ashraf's group [142] in 2001, although no direct experimental evidence was provided to support this proposition. A year later, we postulated and demonstrated for the first time that IPC elicited its cardioprotective effect by targeting and inhibiting the opening of the mPTP [138]. We found that the preconditioning mimetic, diazoxide was able to reduce calcium-induced mPTP opening (measured by the loss of mitochondrial calcein) in adult rat cardiac mitochondria [138], suggesting a link between the MitoK $\mathrm{ATP}_{\text {channel and } \mathrm{mPTP}}$ inhibition. Subsequent studies have confirmed mPTP inhibition in several different settings of preconditioning including: the preconditioned perfused rat heart [143, 144]; the preconditioned adult rat cardiomyocyte $[145,146]$; the anesthetic-preconditioned in vivo rabbit heart [147]; and the rat heart protected by delayed preconditioning $[148,149]$. The mechanism through which IPC actually inhibits the opening of the mPTP at the time of myocardial reperfusion is currently unresolved but several mechanisms have been proposed and are reviewed in a recent review [150].

More controversially, we have suggested that a transient nonlethal form of mPTP opening in response to the IPC protocol may contribute to IPC cardioprotection, by allowing the production of mitochondrial ROS to activate pro-survival kinases such as Akt [151, 152]. Recent imaging studies have reported flickering of the mPTP in intact cardiomyocytes under basal conditions associated with mitochondrial superoxide release [153].

\section{SECOND WINDOW OF PROTECTION}

One or more brief non-lethal episodes of myocardial ischemia and reperfusion can precondition the myocardium to withstand a sustained episode of lethal ischemia-reperfusion injury (termed classical or early ischemic preconditioning, IPC) [1]. The preconditioned state manifests immediately following the IPC stimulus and lasts for 1-2 hours after which it disappears [154]. In 1993, two research laboratories working independently of each other, made the intriguing discovery that the cardioprotective effect actually reappeared 24 hours later (termed the Second Window of Protection or delayed or late IPC). Yellon's group [155] observed infarct-size reduction using an in vivo rabbit model 24 hours following a standard IPC stimulus, suggesting and terming this the Second Window of Protection (SWOP). Kuzuya and co-workers [17] demonstrated myocardial infarct size reduction using an in vivo canine model either immediately or 24 hours following a standard IPC stimulus, but failed to observe an infarct-limiting effect at 3 or 12 hours following the IPC stimulus, confirming the presence of a bi-phasic cardioprotective response to IPC.

Delayed preconditioning can be elicited by both nonpharmacological stimuli (ischemia, heat stress, pacing and exercise) as well as pharmacological stimuli and can protect against myocardial infarction, myocardial stunning, arrhythmias and endothelial dysfunction. The studies which originally described delayed IPC used four-5 minute cycles of myocardial ischemia and reperfusion 
to elicit delayed ischemic preconditioning (delayed IPC) in the rabbit heart [155] and canine heart [17], probably because this was the standard protocol used for eliciting early IPC. However, it has been shown that a single-5 minute cycle is also sufficient to elicit delayed IPC [156].

One of the first studies describing the phenomenon of delayed preconditioning had demonstrated that heat stress could limit myocardial infarct size 24 hours later and this beneficial cardioprotective effect was associated with increased myocardial levels of heat shock protein $72 \mathrm{KD}$ (HSP72) [155]. However, the original experimental study to link heat stress with cardioprotection was published several years earlier by Currie and co-workers in 1988 [157], who first demonstrated that subjecting a rat to whole body hyperthermia $\left(15\right.$ minutes at $42^{\circ} \mathrm{C}$ ) improved post-ischemic ventricular function, reduced cardiac enzyme release in excised perfused hearts, reduced ultra-structural damage to mitochondrial and decreased oxidative stress. Subsequent studies have linked heat stress induced delayed preconditioning with the generation of myocardial heat shock proteins and many of the mediators associated with delayed IPC.

\subsection{Underlying Mechanisms}

Since the original description of SWOP or delayed IPC 18 years ago, the mechanisms underlying this endogenous cardioprotective phenomenon have been the subject of intense investigation (see (Fig. 2) for overview). Mechanistic pathways are needed in the SWOP (or delayed or late preconditioning) to relay the cardioprotective signal with respect to time, from the initial IPC stimulus to the cardioprotective effect which manifests 24 hours later. The signal transduction pathway underlying delayed IPC requires 'triggers' (substances generated during the IPC stimulus such as adenosine, bradykinin, opioids, cytokines, nitric oxide [NO] or reactive oxygen species [ROS]) which recruit 'early mediators' (such as PKC, tyrosine kinase, PI3K-Akt, MEK1/2-Erk1/2, and JAK), which in turn activate transcription factors (such as STAT1/3, NFkB, AP1 , Nrf2 and HIF-1 $\alpha$ ), resulting in the synthesis 12-24 hours later of 'distal mediators' (such as iNOS, HSP and COX-2) which protect the heart against infarction by acting on 'end-effectors' or 'targets' (such as the mPTP or the $\mathrm{mK}_{\mathrm{ATP}}$ channel). The requirement for the transcription and synthesis of de novo protein cardioprotective mediators is one of the major factors distinguishing delayed from early IPC and it may account for the observed absence of cardioprotection in the 3-12 hours following the IPC stimulus. Clearly, this classification is not rigidly adhered to with some triggers/mediators/effectors difficult to classify under one heading as they may overlap one or more categories.

\section{REMOTE ISCHEMIC CONDITIONING}

“...preconditioning may be mediated by factor(s) activated, produced, or transported throughout the heart during brief ischemia/reperfusion." Przyklenk et al 1993 [8].

The disadvantages of IPC and also IPost are that they require an intervention being applied directly to the heart. Therefore, the ability to condition an organ or tissue away from the heart has facilitated the translation of RIC into the clinical setting. In 1993, Przyklenk and colleagues made the intriguing discovery that inducing brief episodes of ischemia and reperfusion in the circumflex coronary vascular territory had the capacity to reduce MI size, arising from the occlusion and reflow of the LAD coronary artery [8]. This form of intramyocardial protection was later extended to noncardiac organs, with the report that MI size could actually be reduced in the animal heart by inducing brief ischemia and reperfusion in either the kidney [158] or the small intestine [159], immediately prior to the sustained coronary artery occlusion (reviewed in $[160,161])$. The concept of RIPC has now been extended to different organs and tissues such that it has emerged as a true strategy of inter-organ protection against the detrimental effects of acute ischemia-reperfusion injury (IRI) (see (Fig. 3) for overview). The discovery that RIPC could be elicited by inducing the remote ischemic conditioning (RIC) stimulus in the limb [162], by simply inflating and deflating a blood pressure cuff placed on the upper arm or thigh [13], has greatly facilitated the translation of RIC into the clinical setting.

\subsection{The Remote Ischemic Conditioning Stimulus}

The remote ischemic conditioning (RIC) stimulus is more closely related to the IPC protocols in that they are most often characterised by one to four cycles of brief ischemia and reperfusion (most often of 5-15 min duration). In the original study by Pryzklenk et al [8] four-5 min cycles of ischemia and reperfusion were applied to the heart. Interestingly, (most often of 5 min duration) whereas in the first demonstration of remote organ preconditioning by Gho et al [10], only one-15 min cycle of ischemia and reperfusion was applied to the remote organ (in this case intestine and kidney). The clinical translation of RIC required the stimulus to be applied to an organ or tissue which could be easily accessed. In this regard, the discovery that the skeletal muscle of the lower limb could be remotely conditioned to protect the heart against IRI [162] has facilitated the translational process with the subsequent demonstration that the remote conditioning stimulus could be applied to the upper or lower limb of human volunteers and patients to noninvasively protect the heart in clinical settings of IRI [13].

Interestingly, the RIC protocols have not varied much with respect to the timing of the intervention with respect to myocardial ischemia and reperfusion. That is similar protocols have been used in spite of whether it was delivered as a RIPC, RIPerC or RIPost protocol. In the first description of RIPerC by Schmidt et al in 2007 [11] four-5 min cycles of limb ischemia and reperfusion were applied after the onset of myocardial reperfusion. The term RIPost was first introduced by Kerendi et al in 2005 [163], although the one-5 min renal ischemia was applied during myocardial ischemia one minute prior to myocardial reperfusion. The first experimental study to actually begin the RIC protocol at the onset of myocardial reperfusion (the true definition of RIPost) was by Andreka et al in 2009 [12], who demonstrated that applying four $5 \mathrm{~min}$ cycles of limb ischemia and reperfusion, at the inset of myocardial reperfusion could reduce MI size using an in situ porcine model of IRI. The current paradigm of lethal myocardial reperfusion injury suggests that the cardioprotective intervention needs to be applied either prior to or at the immediate onset of myocardial reperfusion to be effective. However, in this RIPost study in which limb ischemia was initiated at the onset of myocardial reperfusion, the cardioprotective factor would have only reached the heart after the limb has been reperfused which would have been after 5 min of myocardial reperfusion had elapsed [12]. This intriguing finding suggests that there may be an additional component of lethal myocardial reperfusion injury which can be targeted, late into reperfusion.

\subsection{Potential Mechanisms Underlying RIC}

The actual mechanism through which an episode of brief ischemia and reperfusion in an organ or tissue exerts protection against a subsequent sustained insult of ischemia-reperfusion injury in a remote organ or tissue is currently unclear (see (Fig. 4) for overview). Experimental studies suggest that many of the underlying mechanistic pathways and signal transduction cascades activated within the protected organ may be similar to those recruited in the setting of IPC and IPost [164]. Mechanistic pathways are needed to relay the cardioprotective signal from the remote preconditioned organ or tissue to the heart. However, once the cardioprotective signal has reached the heart, similar signaling pathways underlying IPC and IPost are then believed to mediate the protec- 


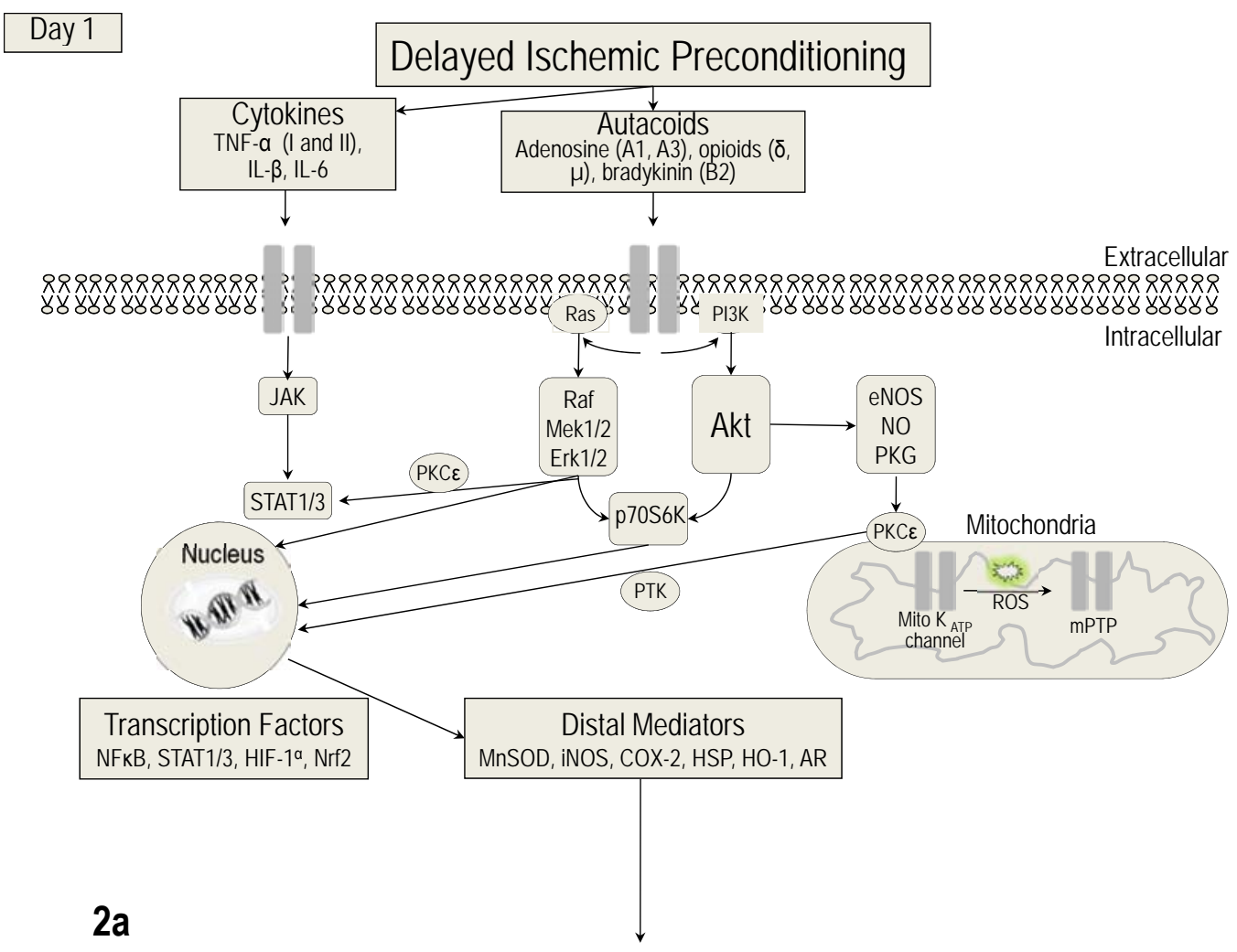

Day 2-3

\section{Re-activation of reperfusion signaling pathways (?Adenosine, ?Bradykinin, ?Opioids)}

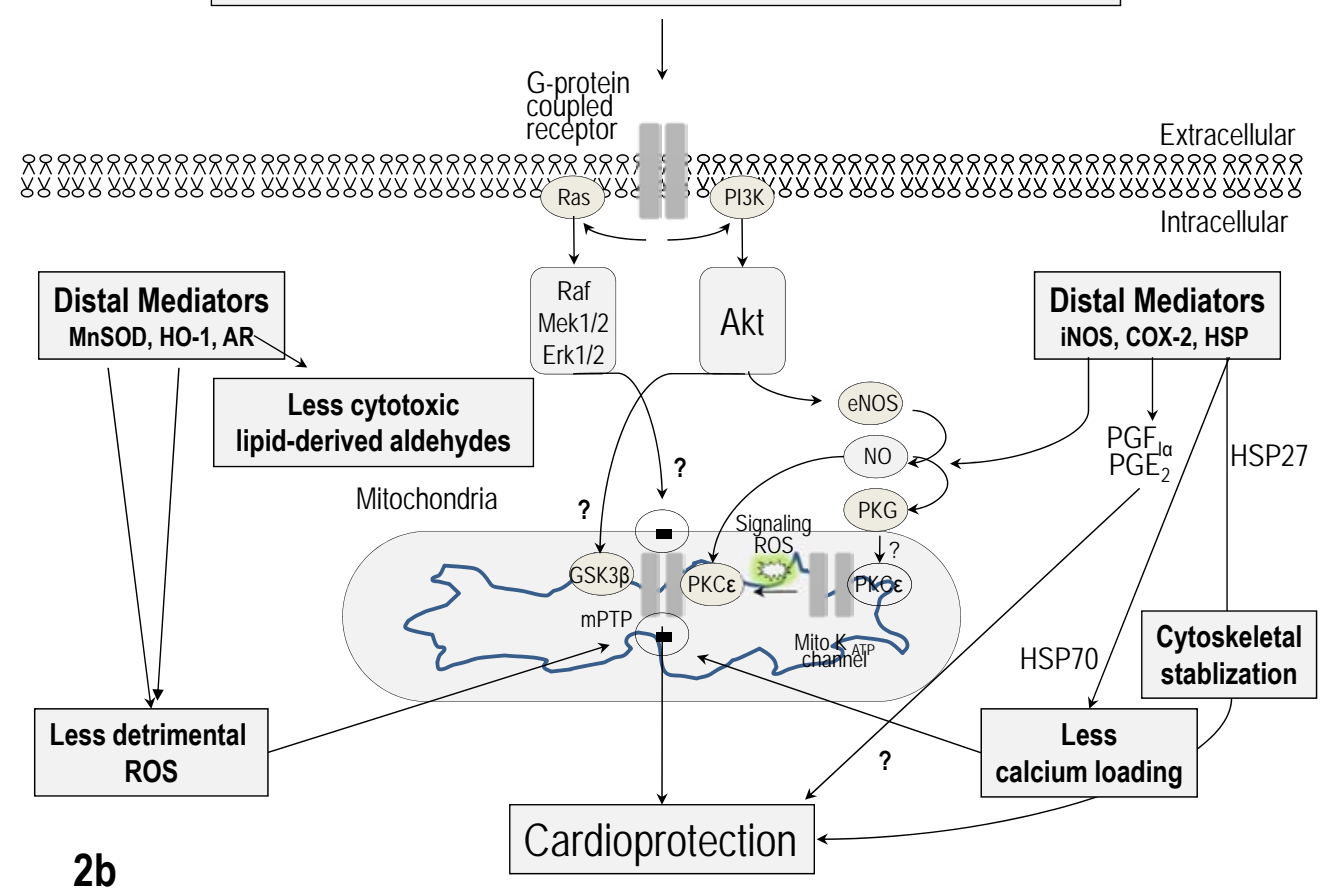

Fig. (2). Signaling pathways underlying delayed preconditioning or SWOP. Overview of major signal transduction pathways underlying delayed ischemic preconditioning (IPC) or the second window of protection (SWOP): (a) On day 1, delayed IPC generates trigger factors such as adenosine (acting via adenosine A1 and A3 receptors), opioids (acting via $\delta$ and $\mu$ opioid receptors) and bradykinin (acting via the bradykinin B2 receptor) which activate intracellular signalling pathways PIK3-Akt, Raf-MEK1/2-Erk1/2, and protein tyrosine kinase (PTK) which convey the cardioprotective signal to downstream pathways such as

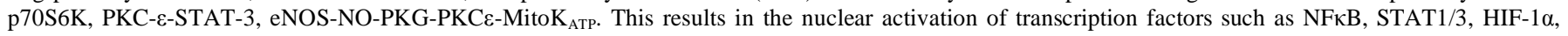


Nrf2, which transcribe de novo proteins (distal mediators) over the next 12-24 hours such as MnSOD, iNOS, COX-2, heat shock proteins (HSP), hemeoxygenase-1 (HO-1), aldose reductase (AR), which then recruit cardioprotective pathways 24-48 hours later on the day of lethal insult of ischemia and reperfusion injury (IRI). In response to the delayed IPC stimulus the generation of cytokines such as TNF- $\alpha$ (acting via the TNF- $\alpha$ receptors I and II), IL- $\beta$, and IL-6, which activate the JAK-STAT pathway also resulting in the transcription of distal mediators. At the level of the mitochondria the opening of the mitoK ${ }_{\text {ATP }}$ channel results in the release of signalling reactive oxygen species, which further activate protein kinases such as Erk1/2 and Akt. The opening sensitivity of the mitochondrial permeability transition pore (mPTP) is decreased by the IPC stimulus, which confers cardioprotection 24-48 hours later in response to the IRI (b) On day 2-3, the activated distal mediators confer cardioprotection at the time of myocardial infarction or stunning through a variety of pathways. The nitric oxide generated by iNOS mediates cardioprotection by inhibiting mPTP opening. The activation of COX-2 generates prostaglandins PGE 2 and PGF P $_{1 \alpha}$ which then mediate cardioprotection through an unclear mechanism. MnSOD and HO-1 exert an antioxidant effect reducing detrimental ROS generated during IRI which may mediate cardioprotection by inhibiting mPTP opening at the time of myocardial reperfusion. The activation of AR mediates cardioprotection by decreasing cytotoxic lipid-derived aldehydes. The pro-survival kinases such as Erk1/2 and Akt are activated at the onset of myocardial reperfusion and confer cardioprotection through mPTP inhibition via GSK3 $\beta$ and the $\mathrm{mK}_{\mathrm{ATP}}$ channel. Whether autocoids such as adenosine, bradykinin or opioids activate these kinases at the time of myocardial reperfusion in unknown. The activation of HSP27 and HSP70 mediate cardioprotection by beneficial effects on stablization of the actin cytoskeleton and calcium regulation, respectively. (Figure reproduced from [18]).

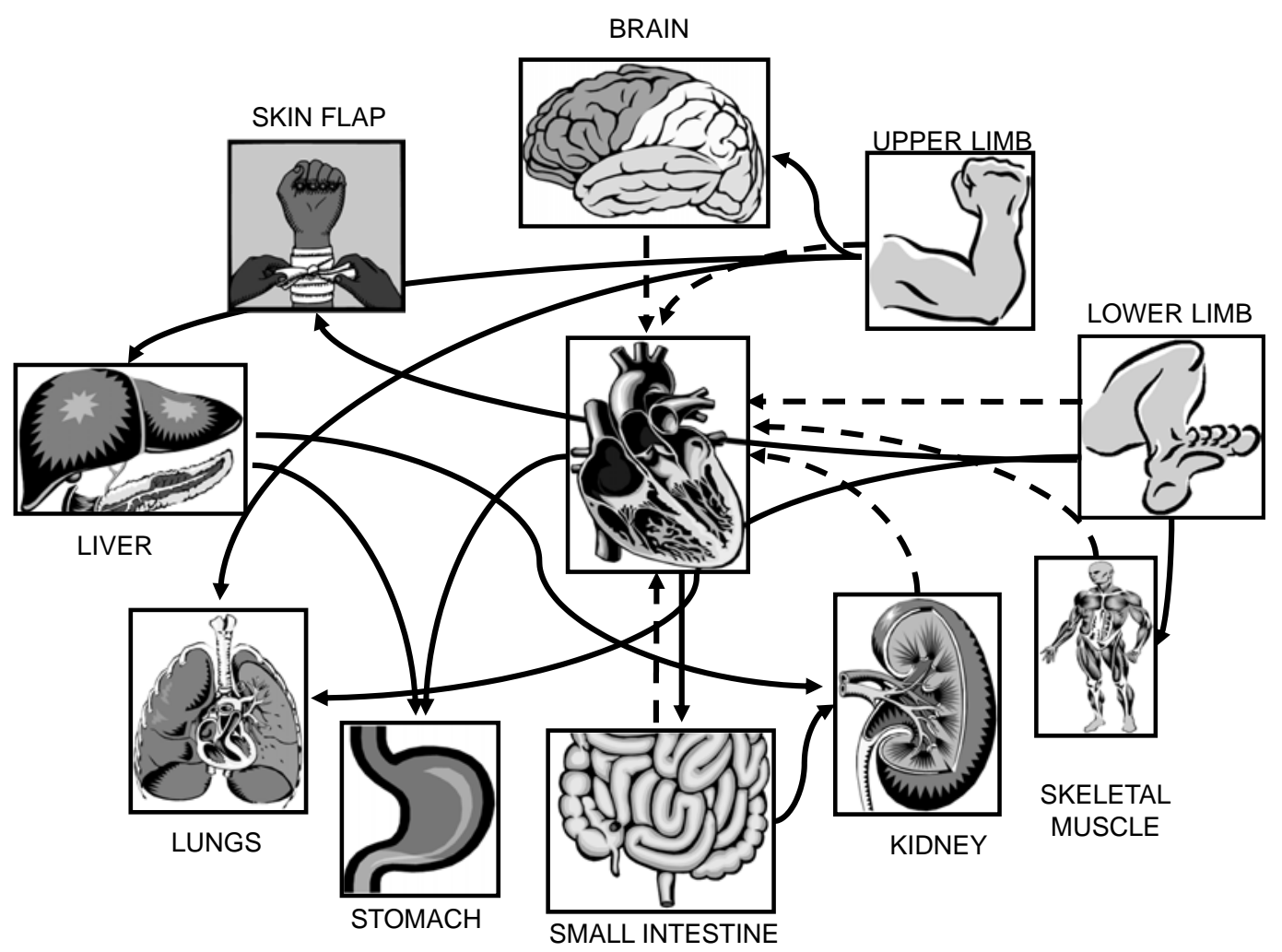

Fig. (3). Inter-organ protection against acute lethal ischemia-reperfusion injury. This cartoon depicts the evolution of remote ischemic preconditioning from a concept that was initially used to describe intramyocardial cardioprotection across coronary vascular territories. It was then demonstrated that brief ischemia and reperfusion of organs or tissue remote from the heart had the ability to protect the myocardium against acute lethal ischemia-reperfusion injury (see dashed black arrows). The concept has now been expanded between non-cardiac organs and tissues such that it represents a general form of inter-organ protection against acute lethal ischemia-reperfusion injury (solid black arrows link the remotely preconditioned organ or tissue to the protected target organ or tissue). (Figure reproduced from [7]).

tive effect. However, the mechanistic pathway linking the remote organ or tissue to the heart is currently unclear although several mechanisms have been proposed. It is important to appreciate that these mechanistic pathways may interact with each other and are therefore not mutually exclusive.

\subsection{Evidence for a Potential Humoral Factor in RIC}

The finding that sustained ischemia of the remote organ was unable to protect the heart and that a period of reperfusion of the remote organ was required, suggested that the reperfusion period may be needed to 'washout' a substance or humoral factor generated by the preconditioning ischemia, which was then transported to the heart [10, 158]. This hypothesis was further supported by a study reporting that blood taken from a rabbit which had been subjected to simultaneous IPC of both the heart and kidney, could reduce a subsequent myocardial infarct size by $77 \%$ when transfused to an untreated rabbit [165], suggesting the transfer of one or more humoral cardioprotective factors. The same authors went onto demonstrate that coronary effluent from an isolated rabbit heart treated with a standard ischemic preconditioning protocol, could reduce myocardial infarct size by $69 \%$ [166] and improve recovery of left ventricular function [167] when used to perfuse an untreated isolated rabbit heart.

Convincing evidence in support of a humoral mechanism for RIPC was provided in an elegant experimental study by Konstantinov et al [168]. Remote limb preconditioning of a pig that had received a donor heart was able to reduce myocardial infarct size in the denervated donor heart, providing strong evidence that a humoral mediator was responsible for RIPC protection, although an afferent sensory nerve pathway from the limb cannot be excluded [168]. A similar type of study was conducted by Kristiansen and colleagues [169] who demonstrated that hearts excised from a rat 


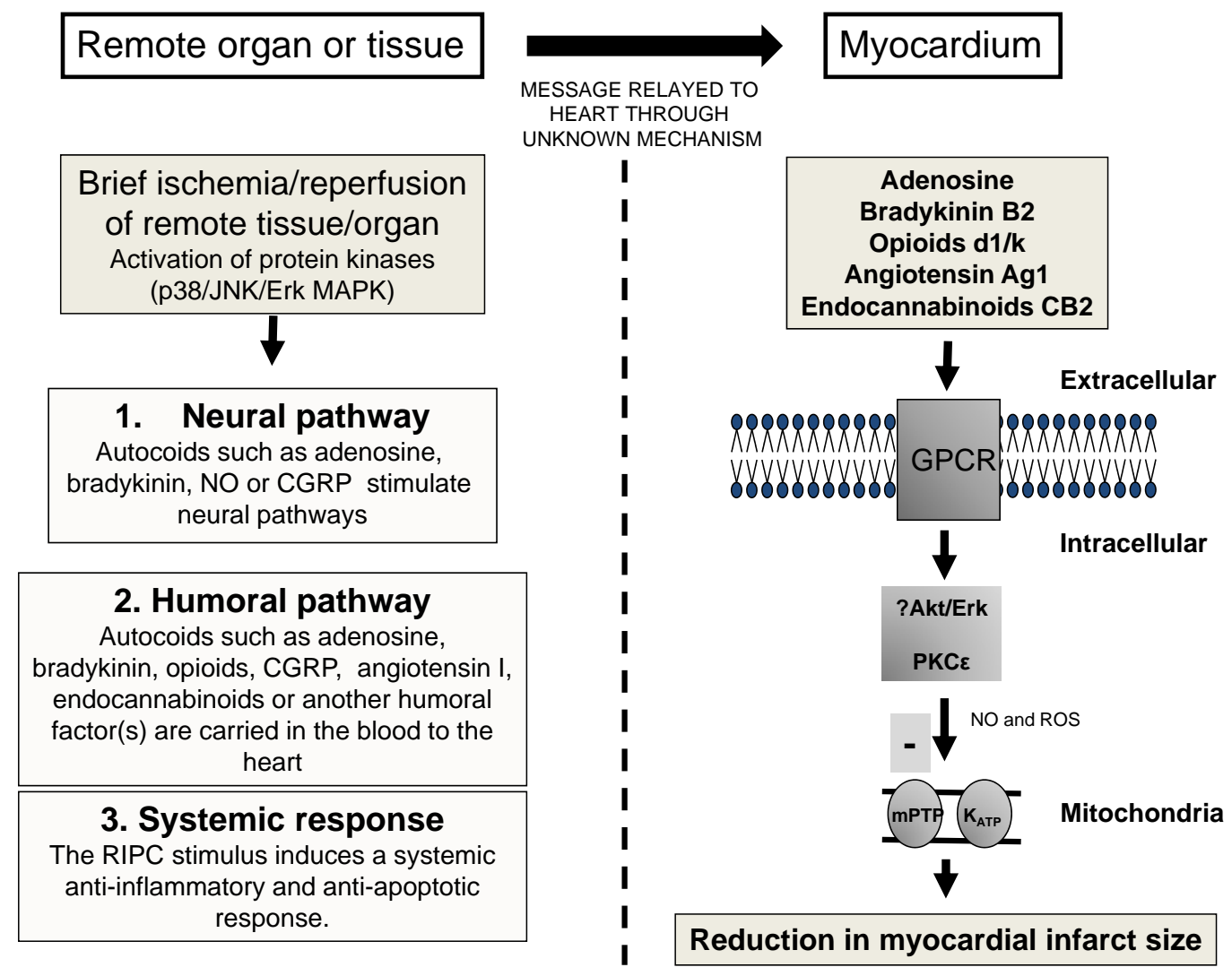

Fig. (4). Signaling pathways underlying remote ischemic preconditioning. The actual mechanism through which episode of brief ischemia and reperfusion in an organ or tissue remote from the heart protects the myocardium from acute IRI is currently unknown, although several hypotheses have been proposed and these are depicted in this figure: (1) The remotely preconditioned organ or tissue generates an endogenous substance such as adenosine, bradykinin or calcitonin gene-related peptide (CGRP), which then activates a local afferent neural pathway stimulating an efferent neural pathway, which terminates on the heart and mediates cardioprotection. (2) The remotely preconditioned organ or tissue generates an endogenous substance (such as adenosine, bradykinin, opioids, CGRP, endocannabinoids, Angiotensin I) or some other as yet unidentified humoral factor(s) which enters the blood stream and activates its respective receptor in the myocardium thereby recruiting the various intracellular pathways of cardioprotection; (3) The remotely preconditioned organ or tissue provokes a systemic protective response which suppresses inflammation and apoptosis. (Figure reproduced from [7]).

that had been remote limb preconditioned experienced a smaller infarct size, when subjected to IRI. Other studies have investigated whether endogenous substances such as adenosine [170], bradykinin [171], opioids [172], CGRP [173], and endocannabinoids [174], are released from the remote organ during the preconditioning ischemia and are carried to the heart in the blood stream where they then activate intracellular pathways of cardioprotection. Alternatively, the endogenous mediator may activate afferent neural pathways within the remote preconditioned organ to confer cardioprotection, as is the case with adenosine, bradykinin and CGRP.

In 1998, our laboratory was the first to implicate adenosine as a potential mediatory factor underlying cardioprotection in the setting of RIPC, demonstrating that the administration of the non-specific adenosine receptor antagonist, 8-sulphophenyltheophylline (8SPT), prior to the RIPC protocol could abolish the reduction in myocardial infarct size induced by a remote preconditioning stimulus in the rabbit kidney [170]. In a subsequent study by Takao and colleagues [175], it was demonstrated that 8-SPT administered after the renal RIPC stimulus also had the ability to block cardioprotection suggesting that myocardial adenosine receptor binding was required for cardioprotection, a finding which was supported by their finding of elevated plasma levels of adenosine in blood sampled from the carotid artery of rabbits subjected to RIPC compared to those treated with IPC alone [175].

The involvement of opioid signaling in RIPC was first reported by Patel and colleagues in 2002 [172]. They demonstrated that the non-specific opioid receptor antagonist, naloxone, was capable of abolishing the myocardial infarct-limiting effects conferred by remote intestinal preconditioning in the rat [172]. It has been proposed that endogenous opioids generated by the preconditioning stimulus in the remote organ enter the blood stream where they act directly on the myocardium to confer cardioprotection [172], although further studies are required to both investigate this proposal and delineate the individual contributions of the different receptor subtypes to RIPC.

Previous studies have implicated binding at the CB2 endocannabinoid receptor of the endogenous cannabinoid system in protection from myocardial ischemia reperfusion injury [176]. A recent experimental study has implicated endogenous activation of the CB2 receptor in the myocardial infarct-limiting effects of remote intestinal preconditioning, using a pharmacological CB2 antagonist to abolish RIPC protection [174]. The authors proposed that endocannabinoids generated by the intestinal ischemia may enter the blood stream and activate $\mathrm{CB} 2$ receptors on the myocardium, but of course further studies are required to test this hypothesis.

\subsection{What is the Identity of the Cardioprotective Factor in RIC}

The possibility of a cardioprotective factor being transferred from the remote conditioned organ or tissue to the heart was first proposed in the initial RIC studies from 1993 [8] and 1996 [10], and yet the identity of the factor(s) involved remains unknown. Several experimental studies have attempted to identify the cardio- 
protective factor(s) in remote preconditioned effluent or plasma using biochemical (chromatography) and mass spectrometry techniques but the identity of the protective factor(s) remains elusive [177-180]. To summarize, these studies have suggested that the cardioprotective factor(s) are probably thermo-labile hydrophobic substances (probably peptides) between 3.5 to $8 \mathrm{kDa}$ in size which have been demonstrated to act via the opioid receptor, PKC, and the PI3K-Akt pathway [177-181]. Whether the same protective factor(s) is released by different remotely conditioned organs or tissues is unknown as is whether the factor(s) have similar protective effects depending on the target organ or tissue. Furthermore, the interplay between the cardioprotective factor(s) and the neural pathway remains unclear. Interestingly, it has been recently shown that the plasma from remote limb preconditioned human volunteers protected rabbit cardiomyocytes from simulated IRI, suggesting cross-species cardioprotection [180].

\subsection{Evidence for a Potential Neural Pathway in RIC}

One of the early studies of RIPC first provided potential evidence that a neural pathway may underlie the cardioprotection elicited by remote preconditioning a non-cardiac organ. Gho and colleagues [10] demonstrated that the reduction in myocardial infarct size induced by brief ischemia and reperfusion of the anterior mesenteric artery could be reversed in the presence of the ganglion blocker, hexamethonium. The hypothesis for a neural pathway was further developed with the proposition that endogenous substances such as adenosine [170], bradykinin [171], calcitonin gene-related peptide (CGRP) [173], released by the remote preconditioned organ, stimulated afferent nerve fibres, which then relayed to efferent nerve fibres terminating on the myocardium to confer cardioprotection.

Ding and colleagues [182] have demonstrated that renal nerve section abolished the cardioprotective effect induced by a remote renal preconditioning stimulus providing strong supportive evidence of a neural pathway. They then reported that during the remote renal preconditioning stimulus renal afferent nerve discharge was increased and that this enhanced neural activity could be abrogated by 8 -SPT [182]. Further confirmatory evidence implicating adenosine in a neural pathway of cardioprotection was provided by Liem and colleagues [183] who after confirming that the prior administration of hexamethonium or 8-SPT abolished the myocardial infarct size reduction induced by brief mesenteric ischemia and reperfusion, demonstrated that the local administration of adenosine into the mesenteric vascular bed also conferred cardioprotection in a manner which was sensitive to hexamethonium [183]. These findings suggested that brief episodes of ischemia of the small intestine may generate adenosine which would then activate mesenteric afferent sensory nerves. However, the investigators went on to report that 8-SPT administered after the remote preconditioning stimulus was also able to inhibit cardioprotection, suggesting that adenosine receptor binding in the heart may also be required for protection [183].

Schoemaker \& van Heijningen [171] demonstrated that the reduction in myocardial infarct size elicited by brief mesenteric artery occlusion and reperfusion could be abolished by prior administration of HOE140, a specific bradykinin B2 receptor antagonist. Interestingly, they went on to find that intra-mesenteric arterial administration of bradykinin was also able to confer cardioprotection in a manner which was sensitive to ganglion blockade by hexamethonium [171]. The authors suggested that bradykinin generated during the remote preconditioning intestinal ischemia, may stimulate mesenteric afferent sensory nerves which then mediate the cardioprotective effect [171]. These findings were confirmed in a subsequent study by Wolfrum and colleagues [184], who also observed that the activation of myocardial PKC- $\varepsilon$ by brief intestinal ischemia was blocked by HOE-140 and hexamethonium, suggest- ing that PKC- $\varepsilon$ was positioned downstream of bradykinin and the neural pathway.

Several experimental studies have implicated calcitonin-gene related peptide (CGRP), a neurotransmitter released from capsaicinsensitive sensory nerves, as a potential mediator of both ischemic preconditioning [185] and RIPC [173, 186]. These can be summarized as follows: remote intestinal preconditioning generates nitric oxide which stimulates capsaicin-sensitive sensory nerves in the intestinal vasculature, releasing CGRP into the blood-stream (where levels have reported to be increased by RIPC), which is then carried to the heart where it activates myocardial PKC- $\varepsilon$. [185, 187].

\subsection{Evidence for a Systemic Response in RIC}

Several experimental studies have examined the effect of remote preconditioning of an organ or tissue on the myocardial gene transcription profile $[188,189]$, and the inflammatory response [190], and have discovered that the inflammatory response is suppressed and a favourable profile of gene transcription appears to be activated that is both anti-inflammatory and anti-apoptotic. The relevance of such a response to the cardioprotective effect elicited by RIPC is currently unclear and requires further investigation.

\subsection{Myocardial Mechanisms of Cardioprotection in RIC}

Once the cardioprotective signal has been conveyed from the remotely preconditioned organ to the heart, intracellular signal transduction mechanisms are recruited within cardiomyocytes which are similar to those that participate in IPC and IPost [191]. These include the ligand binding to G-protein cell surface coupled receptors such as adenosine [170], bradykinin [171], opioids [172], angiotensin [192], and endocannabinoids [174]. The binding to these cell surface receptors appears to then activate intracellular kinases such as PKC-E [184] and other signalling components such as reactive oxygen species [193], nitric oxide and the mitochondrial KATP channel [170]. Whether RIPC also activates pro-survival kinases of the Reperfusion Injury Salvage Kinase (RISK) pathway and results in the inhibition of the mitochondrial permeability transition pore (mPTP), as in IPC and IPost, remains to be determined [164]. It has been recently shown that coronary effluent collected from IPC-treated hearts can protect naïve isolated perfused rat hearts when administered at the onset of myocardial reperfusion through the activation of the PI3K-Akt component of the RISK pathway [181].

\subsection{Novel Concepts in RIC}

Recent studies suggest that the heart can be protected from acute IRI by simply inducing surgical trauma elsewhere- a phenomenon which has been termed remote preconditioning of trauma (RPCT) [194, 195]. Jones et al [195] demonstrated that an abdominal surgical incision was enough to protect the murine heart from MI. The mechanistic pathway underlying this cardioprotective effect appeared to be mediated through a neural pathway involving sensory fibres, spinal nerves and cardiac sympathetic nerves which via bradykinin activated myocardial intracellular mediators of cardioprotection such as PKC and MitoKATP channel. Somewhat remarkably, the cardioprotection could be recapitulated by simply applying capsaicin cream to stimulate the $\mathrm{C}$ sensory fibres in the skin. RPCT has recently been confirmed in a canine model of IRI with a surgical abdominal incision reducing subsequent MI size [196].

A recent experimental study has suggested that the heart can be repeatedly remote ischemic postconditioned (RIPost) post-MI to elicit beneficial effects on LV remodelling [197]. Wei et al [197] found that repeating the RIPost stimulus either every day or every 3 days for 28 days reduced adverse LV remodelling post-MI and improved survival at 84 days post-MI. Whether repeated RIPost every 3 days, in post-MI patients has beneficial effects on LV remodeling is an intriguing possibility. 


\section{ISCHEMIC POSTCONDITIONING}

In 2003, Zhao et al [19] made the surprising observation that interrupting myocardial reperfusion with several short-lived episodes of myocardial ischemia was cardioprotective. These authors found that by applying three-30 second cycles of alternating LAD reperfusion and LAD occlusion at the onset of myocardial reperfusion could reduce MI size by $44 \%$ in the canine heart [19]. Interestingly the term ischemic "postconditioning" had first been coined in an earlier experimental study by $\mathrm{Na}$ et al in 1996 [198] in which it was demonstrated that intermittent reperfusion achieved by ventricular ectopic beats could reduce reperfusion arrhythmias in a feline model of IRI. In fact, the concept of intermittent or gradual reperfusion as a cardioprotective strategy was first investigated in the 1980's [199, 200] but it is the term IPost which has captured the imagination of the research field of cardioprotection.

The discovery of IPost as therapeutic cardioprotective strategy which can be applied at the onset of myocardial reperfusion has revitalized interest in lethal myocardial reperfusion injury as a target for cardioprotection and provided solid evidence for the existence of lethal myocardial reperfusion injury in both animal models and man.

\subsection{The IPost Stimulus}

When compared to the IPC stimulus, which comprises one to four cycles of brief ischemia and reperfusion (most often of $5 \mathrm{~min}$ duration), the IPost stimulus is short-lived consisting of three to six cycles of ischemia and reperfusion (most often of 5-60 sec duration). In the original study by Zhao et al in 2003 [1], myocardial reperfusion was interrupted with three-30 sec cycles of myocardial ischemia. In IPC the brief episodes ischemia and reperfusion are required to induce a change in mitochondrial function whereas in IPost, it is probably the intermittent or stuttered reperfusion which is the most important aspect of the protocol. The IPost protocol varies from species to species with small animal myocardial models of IRI requiring 5 - $10 \mathrm{sec}$ episodes of alternating ischemia and reperfusion whereas larger animal models and humans requiring 30 - $60 \mathrm{sec}$ IPost protocols [201]. With respect to the timing of the administration of the IPost protocol, the current paradigm suggests that it needs to be delivered in the first minute of myocardial reperfusion to be effective. However, a recent experimental study has suggested in the murine model of in situ myocardial IRI, the IPost protocol may be still effective even when administered up to 45 min into myocardial reperfusion, suggesting that delayed postconditioning may be targeting a later component of myocardial reperfusion injury such as apoptosis or inflammation.

A number of pharmacological agents have been reported in experimental studies to reduce MI size when administered at the onset of myocardial reperfusion and have been termed pharmacological postconditioning agents despite the fact that many of them were investigated prior to the concept of IPost was introduced.

In addition to protecting the heart from the known proponents of lethal myocardial reperfusion injury such as oxidative stress, calcium overload, inflammation, mPTP opening, IPost is known to recruit a number of signal transduction pathways many of which are similar to those utilized by IPC.

\subsection{Signaling Pathways Underlying IPost}

The signal transduction pathways underlying IPost are both numerous and complex and only an overview can be given here. For more detailed accounts the reader is kindly directed to the following reviews $[5,202]$. There are many similarities in the endogenous signal transduction pathways underlying classical or acute IPC and IPost in the cardiomyocyte. The obvious difference between the two, however, is the need to have a mechanism in place to mediate the 'memory' effect of IPC to sustain the cardioprotective effect for the first 2-3 hours. In contrast, the cardioprotective effect of IPost is manifested in the first few minutes of myocardial reperfusion.
Whether the IPost stimulus also exerts remote protection to distant organs or tissues or whether it initiates a first and second window of protection in a similar manner to IPC is unknown. In common with IPC, the current paradigm is that the signaling pathway is initiated at the cell membrane surface with the activation of a variety of Gprotein coupled receptors by a number of autacoids (such as adenosine, bradykinin, opioids), the activation of which recruit a wide variety of signal transduction pathways many of which appear to converge on the mitochondria.

\subsubsection{Cell-surface Receptor Activation}

The first G-protein coupled receptor (GPCR) to be linked to IPost was the adenosine receptor. An experimental study by Yang et al in 2005 [203] was the first to observe that the reduction in myocardial infarct size elicited by IPost could be abolished in the presence of 8-p-(sulfophenyl) theophylline (8-SPT), a non-specific adenosine receptor blocker. Interestingly, some 14 years earlier, the same research group had been responsible for first implicating adenosine receptor activation with the phenomenon of IPC [22]. The actual adenosine receptor subtype which is responsible for IPost is unclear with studies implicating the adenosine A1 [204], A2A [205], and A2B [206] receptor subtypes.

A subsequent study by Penna and colleagues [207] has implicated the endogenous activation of the GPCR, bradykinin B2, in IPost protection. These authors first demonstrated that two different pharmacological antagonists of the bradykinin B2 receptor abolished IPost protection in perfused rat hearts [207]. Finally, the recent finding that mice lacking the bradykinin B2 receptor were resistant to IPost protection, provides genetic evidence for the obligatory role of endogenous bradykinin $\mathrm{B} 2$ receptor activation in the setting of IPost [204]. The role for the bradykinin B1 receptor was less clear, as the mice were partially protected by the IPost stimulus [204].

Recently, Zatta and colleagues [208] have linked IPost with the endogenous activation of the opioid GPCR. After demonstrating that the non-specific opioid receptor antagonist, naloxone, was capable of abolishing IPost-protection in the intact rat heart, they investigated the effect of IPost in the presence of pharmacological antagonists of the $\delta$-, $\kappa-$, and $\mu$-opioid receptors [208]. The data implicated endogenous stimulation of the $\mu$ - and possibly the $\delta$ opioid receptors in the setting of IPost [208]. In addition, hearts subjected to IPost accumulated higher levels of pro-encephalin, suggesting perhaps that IPost was capable of increasing endogenous opioid content in the reperfused myocardium [208]. Other receptors which have been implicated in IPost include the protease activated receptor 2 (PAR2) [209] and particulate guanylyl cyclase, the natriuretic peptide receptor [210].

\subsubsection{Signal Transduction Pathways}

A number of different signalling pathways have been investigated in the setting of IPost. The first of these was the Reperfusion Injury Salvage Kinase (RISK) pathway, a group of pro-survival protein kinases which on activation at the onset of myocardial reperfusion confer powerful cardioprotection [211, 212]. We and others have demonstrated that the pharmacological activation of components of the RISK pathway such as Akt and Erk1/2 at the immediate onset of myocardial reperfusion using a diverse variety of agents, which include growth factors, cytokines, GPCR agonists, natriuretic peptide, adipocytokines, and 'Statins' reduce myocardial infarct size in the region of $40-50 \%[211,212]$. Our laboratory and others have demonstrated that the cardioprotective benefits of IPost are dependent on the activation of Akt and Erk1/2 at the immediate onset of myocardial reperfusion [213, 214]. Subsequent studies have confirmed the role for Akt and Erk1/2 in the setting of IPost in both non-diseased animal hearts and diseased ones [215, 216] as well as human atrial muscle [217]. Interestingly, obese mice have been reported to be resistant to IPost protection, and this finding was associated with insufficient activation of the RISK pathway in 
the hearts harvested from obese animals compared to control ones [218]. This finding underscores the importance of using relevant experimental animal models capable of simulating disease pathologies present in patients with coronary heart disease.

The Survival Activating Factor Enhancement (SAFE) pathway, which comprises the TNF- $\alpha$ receptor and Janus Kinase (JAK)Signal transducer and activator of transcription (STAT) pathway, has also been linked to cardioprotection elicited by IPost [219, 220]. Experimental studies have reported that pharmacologically inhibiting the JAK-STAT pathway at the onset of myocardial reperfusion abrogates the infarct-limiting effects of IPost [219, 220]. However, mice with a cardiac-specific STAT3 deletion were found to still be amenable to the infarct-limiting effects of IPost, providing a suitable IPost protocol was used i.e. IPost using $5 \times 5$ sec cycles of ischemia/reperfusion reduced myocardial infarct size but $3 \times 10 \mathrm{sec}$ cycles did not [219]. Using mice with the same cardiacrestricted STAT-3 deletion, Goodman and colleagues [220] were able to demonstrate improved LV function using the IPost protocol of $3 \times 10 \mathrm{sec}$ cycles of ischemia/reperfusion, suggesting that STAT-3 may not be an obligatory mediator of IPost. The mechanism underlying the acute form of myocardial protection mediated by the JAKSTAT pathway is unclear but may relate to as yet unidentified mitochondrial effects [221].

Sphingosine kinase (SPK) is a lipid kinase which generates sphingosine 1 phosphate (S1P), which in turn regulates cell mitosis, apoptosis, cytoskeletal rearrangement, and survival [222]. Jin and colleagues [223] have recently demonstrated an obligatory role for $\mathrm{SPhK} 1$ as a mediator of IPost, which is potentially upstream of the RISK pathway. The authors reported that hearts isolated from mice lacking $\mathrm{SPhK} 1$, sustained larger myocardial infarcts, were resistant to IPost, and did not demonstrate activation of the Akt and Erk1/2 components of the RISK pathway in response to IPost [223].

It is well-established that protein kinase $\mathrm{C}$ acts as a critical mediator of protection in the setting of IPC, providing for the 'memory' elicited by an IPC-stimulus (reviewed in [224]). IPost has been reported to also be dependent on PKC activation. Penna and colleagues [225] were the first to demonstrate that the non-specific PKC inhibitor could abolish the infarct-limiting effects of IPost in perfused rat hearts, suggesting that IPost required the activation of PKC to confer cardioprotection. A subsequent study by Zatta and colleagues [226] has found that IPost-protection could be abolished by pharmacological inhibition of the PKC- $\varepsilon$ isoform in early reperfusion. The translocation to the mitochondria of the detrimental $\mathrm{PKC}-\delta$, was reduced in postconditioned hearts. The mechanism through which IPost activates PKC is unclear. With respect to the cardioprotective effects of $\mathrm{PKC}$, it has been postulated that PKC may sensitize the adenosine A2B receptor on the cell surface [206, 227 ] and that a special mitochondrial pool of PKC- $\varepsilon$ confers inhibition of mitochondrial permeability transition pore (mPTP) opening [121].

Protein kinase G (PKG) has emerged as a critical mediator of cardioprotection in both IPC and IPost (reviewed in [228]). Much of the experimental data suggests that in the setting of IPC, it forms the final link in the signaling pathway which begins at the plasma membrane and terminates at the mitochondria [229]. In the context of IPost, its myocardial infarct-limiting effects have been demonstrated to be sensitive to pharmacological inhibition of the NOsGC-cGMP-PKG pathway [203, 230]. Activated PKG at the level of the mitochondria is then believed to open the ATP-sensitive mitochondrial potassium channel through protein kinase C- $\varepsilon$ [229]. This pathway is presumed to be activated through the Akt component of the RISK pathway via eNOS in response to IPost [213]. The downstream target of this pathway is believed to be PKC, resulting in sensitization of the adenosine A2B receptor [227] or the inhibition of mPTP opening [231, 232].

\subsubsection{Mitochondria and IPost}

Many of the signalling pathways underlying IPost appear to converge on the mitochondria. In this regard, the mitochondrial permeability transition pore (mPTP) has emerged as a critical target for cardioprotection in the setting of IPost (reviewed in [233, 234]). Preventing its opening at the onset of myocardial reperfusion using pharmacological mPTP inhibitors $[138,139,233]$ or genetically ablating one of its critical components [135, 136, 235], reduces myocardial infarct size by $40-50 \%$. IPost [236] has been reported to prevent $\mathrm{mPTP}$ opening at the onset of myocardial reperfusion, although the mechanism underlying this effect is currently unclear. It may involve components of the RISK pathway such as Akt, Erk1/2 or GSK-3 $\beta[237,238]$ and/or changes in intracellular $\mathrm{pH}$ in the first few moments of myocardial reperfusion [76, 77]. Argaud and colleagues [236] found that mitochondria isolated from a perfused rabbit heart which had been subjected to a standard IPost protocol, were more resistant to calcium-induced opening of the MPTP, suggesting that IPost was capable of inhibiting mPTP opening. A subsequent study by the same group, reported that this inhibitory effect on mPTP opening was sensitive to pharmacological PI3K inhibition, suggesting that IPost mediated mPTP inhibition through the activation of the PI3K-Akt pathway [237]. We have demonstrated that mice lacking cyclophilin-D are resistant to IPost providing confirmatory evidence supporting the role of the mPTP in IPost [235]. Further studies suggest that the changes in cellular $\mathrm{pH}$ in early reperfusion of postconditioned hearts may also contribute to the inhibition of mPTP opening [77].

In the first few minutes of myocardial reperfusion there is a rapid restoration of physiological $\mathrm{pH}$ within the cardiomyocyte, mediated by the wash-out of lactic acid and the actions of the Na+$\mathrm{H}+$ exchanger (NHE) and the Na+-HCO- co-transporter. Interestingly, IPost [76, 77, 239] has been reported to delay the restoration of physiological $\mathrm{pH}$ in the early moments of myocardial reperfusion. This transient acidosis in the first couple of minutes of reperfusion may be sufficient to permit the activation of the RISK pathway [76], suppress mPTP opening [77], inhibit cardiomyocyte hypercontracture, and prevent detrimental calpain activation [239], over this critical period of time. The mechanism through which IPost modifies cellular $\mathrm{pH}$ in early reperfusion is currently unclear, but it has been attributed to delayed wash-out of lactate, but another potential explanation could be the inhibition of the NHE by the RISK pathway, which is activated in IPost-treated hearts. A recent study by Avkiran's laboratory [240] has demonstrated that Akt is able to phosphorylate and inhibit the actions of NHE in cardiomyocytes, and so whether this process occurs in postconditioned hearts is an interesting possibility.

Previous experimental studies have suggested that the ATPsensitive mitochondrial potassium (MitoKATP) channel plays a pivotal role in IPost, although much of the evidence is circumstantial and based on the use of pharmacological activators and inhibitors of the channel. Studies have demonstrated that the pharmacological inhibition of the MitoKATP channel in early reperfusion abolished the infarct-limiting effects of IPost [214, 241, 242].

IPost [19] has been reported to reduce the amount of detrimental ROS generated at the onset of myocardial reperfusion. In contrast, ROS may also participate as critical signaling mediators in the signal transduction pathway underlying IPost [225]. Penna and colleagues [225] were the first to demonstrate that the administration of the non-specific ROS scavenger, N-acetylcysteine (NAC), was able to abrogate the infarct-limiting effect of IPost in perfused rat hearts. Crucially, if NAC was administered after the first three minutes of myocardial reperfusion had elapsed, no effect on IPost was observed, suggesting that ROS signaling during the first couple of minutes of myocardial reperfusion was critical to IPost protection [225]. Subsequent studies using intact rabbit [243] and murine [244] hearts have confirmed the involvement of a signaling form of ROS in IPost protection. 


\section{EMERGING CONCEPTS IN ISCHEMIC CONDITIONING}

\subsection{Combining Different Ischemic Conditioning Stimuli}

The difference in the 'timing' and the 'site or delivery' of the 3 different forms of ischemic conditioning, provide the possibility of combining different ischemic conditioning protocols to achieve either additive or synergistic cardioprotection. The belief that underlying mechanisms may be similar across the three forms of ischemic conditioning and the limitations of the current animal models of IRI in terms of resolution of cardioprotection may also have contributed to the lack of enthusiasm for combining different protocols. IPC has been tried in combination with IPost by several investigators with inconclusive findings [213, 245, 246]. Recent experimental studies have combined RIPerC with IPost protocols and observed additive cardioprotection, although no additive effect was observed when combined with IPC [247]. Further investigation is now required to explore the possibility of combining ischemic conditioning protocols in the clinical setting.

\subsection{Gene Therapy for Cardioprotection}

The identification of iNOS as a distal mediator of delayed cardioprotection has been investigated as a therapeutic strategy using gene therapy to adenovirally transfect adult murine hearts with iNOS, a strategy which resulted in infarct-size limitation, through a mechanism involving COX-2 [248]. Similar findings have been reported with Ec-SOD adenoviral transfection [249, 250]. The same authors are exploring the possibility of adenoviral transfection of other known distal mediators (such as COX-2) of delayed cardioprotection as a strategy for long-term "prophylactic cardioprotection' in animal models (reviewed in [251]). The possibility of maintaining the heart in a state of cardioprotection is particularly attractive given the unpredictable onset of acute coronary syndromes. However, the long-term consequences of prolonged activation of cardioprotective mediators such as iNOS and COX-2 would have to be investigated. In this regard, Li et al $[252,253]$ have demonstrated that adenoviral transfection of murine hearts with heme oxygenase-1 or iNOS resulted in long-term cardioprotection with MI size reduction at one year with no adverse functional effects.

\subsection{Regenerative Therapy for Cardioprotection}

Regenerative therapy using stem cells as a treatment strategy for coronary heart disease remains an ongoing area of research interest and has been recently been investigated in the setting IPC in two areas. In the first area, IPC has been used as a therapeutic strategy for improving survival and engraftment of bone marrow derived stem cells [254]. The second area the focus has been on the potential role of bone marrow derived stem cells as 'mediators' of delayed IPC. Li and co-workers [255] found using an in vivo murine model that a standard IPC stimulus could recruit into the myocardium bone marrow-derived endothelial progenitor cells (EPC) within 3 hours, and that these cells 'imported' cardioprotective mediators such as iNOS and eNOS into the ischemic myocardium. In human volunteers, repeated episodes over one month of remote ischemic preconditioning induced by brief cycles of ischemia and reperfusion of the arm, has been reported to be associated with an increase in circulating EPC's and improved endothelial function [256], but the contribution of the EPC's to these beneficial endothelial effects are unclear. In a subsequent study, Kamota and coworkers [257] demonstrated using an in vivo murine model that IPC induced by brief cycles of occlusion and reperfusion of the aorta (remote preconditioning stimulus) had several beneficial effects 24 hours later including reduced myocardial infarct size, preserved LV ejection fraction, augmented peripheral circulating levels of CD34+ and flk-1+ bone marrow stem cells (BMSC), increased myocardial targeting to the ischemic risk zone of GFP-tagged BMSC. The IPC stimulus was reported to increase levels of serum vascular endothelial growth factor and stromal cell-derived factor-1 $\alpha$ [257]. Crucially, using antibodies to abrogate the IPC-induced elevation and targeting of BMSC, also abolished the cardioprotective benefit. Clearly, the mechanism underlying the cardioprotective benefits of BMSC are unclear but over a relatively short time interval (24 hours) [257], the release of cardioprotective humoral factors by BMSC into the infarcted myocardium would seem a possible explanation.

\subsection{Neural Pathways in Cardioprotection}

It has been suggested that neural pathways are involved in mediating the cardioprotective stimulus from the remote conditioned organ or tissue to the target organ or tissue in the setting of RIC [7]. Whether neural pathways are also involved in IPC is an interesting unanswered question. Kudej and co-workers [258] demonstrated that regional cardiac denervation of the porcine heart abrogated the in vivo infarct-limitation provided by delayed IPC and prevented the upregulation of myocardial iNOS and COX-2, established mediators of delayed cardioprotection. However, the cardioprotection elicited by early IPC was not affected [258]. Whether cardiac innervation is required during the IPC stimulus or at the time of myocardial infarction is unclear. Clearly, further work needs to be undertaken to examine the role cardiac nerves contribute to delayed IPC. In this respect, hearts excised from remote limb preconditioned rats generated smaller infarcts on the Langendorff-apparatus [169], suggesting that cardiac innervation at the time of infarction may not be necessary for cardioprotection, presumably because the heart was already in a preconditioned state.

\subsection{MicroRNAs and Cardioprotection}

MicroRNAs (miRNAs) are noncoding RNAs involved in the post-transcriptional regulation of protein expression, which have been recently implicated in cardiac development, cardiac hypertrophy, cardiac failure and arrhythmogenesis (reviewed in [259]). It has been demonstrated that miRNA's may contribute to classical IPC cardioprotection [260]. Yin and co-workers [261] initially demonstrated that heat stress of mice increased peripheral circulating levels of miRNA's 1, 21, and 24, which when isolated and injected into naïve mice conferred cardioprotection 24 hours later in Langendorff-perfused hearts. A subsequent study by the same groups found a similar serum miRNA profile produced in response to a standard IPC [262]. In this case, the isolated and purified miRNA were injected into the LV wall and resulting in infarct size limitation 48 hours later, a finding which was associated with upregulation of eNOS, HSP70, and the HSP70 transcription factor (HSF-1) [262], known mediators of delayed cardioprotection. Clearly, further work is required to determine how the IPC stimulus generates miRNA and which proteins or kinases are modified by miRNA in the context of delayed IPC. Another intriguing possibility is whether miRNA could act as the humoral factor(s) conveying cardioprotection from the distal remote preconditioned organ or tissue to the heart.

\section{CONCLUSION}

The phenomenon of ischemic preconditioning has evolved into a number of different forms including remote ischemic conditioning and ischemic postconditioning, a process which has facilitated its translation into the clinical setting of cardioprotection. Ongoing experimental studies continue to elucidate the mechanisms underlying these 3 different forms of endogenous cardioprotection and over the years huge progress has been made towards the understanding of adaptation of the cardiomyocyte to ischemia-reperfusion injury and the intracellular signal transduction pathways that mediate this process. Proof-of-concept clinical studies have demonstrated beneficial effects with ischemic preconditioning, ischemic postconditioning and remote ischemic conditioning in a variety of clinical settings and reviewed in another article in this special issue. Therefore, harnessing the powerful cardioprotection elicited by ischemic preconditioning, remote ischemic conditioning, and ischemic postconditioning could one day provide a therapeutic strategy for pro- 
tecting the heart against acute IRI, preserving cardiac function and improving clinical outcomes in patients with ischemic heart disease.

\section{CONFLICT OF INTEREST}

The authors confirm that they have no conflicts of interest.

\section{ACKNOWLEDGEMENTS}

I would like to thank the British Heart Foundation (FS/10/039/ 28270) and RoseTrees Trust for ongoing funding and support. This work was undertaken at University College London Hospital/University College London (UCLH/UCL) who received a proportion of funding from the Department of Health's National Institute of Health Research (NIHR) Biomedical Research Centres funding scheme.

\section{REFERENCES}

[1] Murry CE, Jennings RB, Reimer KA. Preconditioning with ischemia: a delay of lethal cell injury in ischemic myocardium. Circulation 1986; 74(5): 1124-36.

[2] Swain JL, Sabina RL, Hines JJ, Greenfield JC, Jr., Holmes EW. Repetitive episodes of brief ischaemia $(12 \mathrm{~min})$ do not produce a cumulative depletion of high energy phosphate compounds. Cardiovasc Res 1984; 18(5): 264-9.

[3] Reimer KA, Murry CE, Yamasawa I, Hill ML, Jennings RB. Four brief periods of myocardial ischemia cause no cumulative ATP loss or necrosis. Am J Physiol 1986; 251(6 Pt 2): H1306-H1315.

[4] Yellon DM, Downey JM. Preconditioning the myocardium: from cellular physiology to clinical cardiology. Physiol Rev 2003; 83(4): 1113-51.

[5] Ovize M, Baxter GF, Di Lisa F, et al. Postconditioning and protection from reperfusion injury: where do we stand? Position paper from the Working Group of Cellular Biology of the Heart of the European Society of Cardiology. Cardiovasc Res 2010; 87(3): 406-23.

[6] Hausenloy DJ, Yellon DM. The Second Window of Preconditioning (SWOP) Where Are We Now? Cardiovasc Drugs Ther 2010 May 23.

[7] Hausenloy DJ, Yellon DM. Remote ischaemic preconditioning: underlying mechanisms and clinical application. Cardiovasc Res 2008; 79(3): 377-86.

[8] Przyklenk K, Bauer B, Ovize M, Kloner RA, Whittaker P. Regional ischemic 'preconditioning' protects remote virgin myocardium from subsequent sustained coronary occlusion. Circulation 1993; 87(3): 893-9.

[9] Whittaker P, Przyklenk K. Reduction of infarct size in vivo with ischemic preconditioning: mathematical evidence for protection via non-ischemic tissue. Basic Res Cardiol 1994; 89(1): 6-15.

[10] Gho BC, Schoemaker RG, van den Doel MA, Duncker DJ, Verdouw PD. Myocardial protection by brief ischemia in noncardiac tissue. Circulation 1996; 94(9): 2193-200.

[11] Schmidt MR, Smerup M, Konstantinov IE, et al. Intermittent peripheral tissue ischemia during coronary ischemia reduces myocardial infarction through a KATP-dependent mechanism: first demonstration of remote ischemic perconditioning. Am J Physiol Heart Circ Physiol 2007; 292(4): H1883-H1890.

[12] Andreka G, Vertesaljai M, Szantho G, et al. Remote ischaemic postconditioning protects the heart during acute myocardial infarction in pigs. Heart 2007; 93(6): 749-52.

[13] Kharbanda RK, Mortensen UM, White PA, Kristiansen SB, Schmidt MR, Hoschtitzky JA, Vogel M, Sorensen K, Redington AN, MacAllister R. Transient limb ischemia induces remote ischemic preconditioning in vivo. Circulation 2002; 106(23): 28813.

[14] Cheung MM, Kharbanda RK, Konstantinov IE, et al. Randomized controlled trial of the effects of remote ischemic preconditioning on children undergoing cardiac surgery: first clinical application in humans. J Am Coll Cardiol 2006; 47(11): 2277-82.

[15] Botker HE, Kharbanda R, Schmidt MR, et al. Remote ischaemic conditioning before hospital admission, as a complement to angioplasty, and effect on myocardial salvage in patients with acute myocardial infarction: a randomised trial. Lancet 2010; 375(9716): 727-34.
[16] hoole SP, Heck PM, Sharples L, et al. Cardiac Remote Ischemic Preconditioning in Coronary Stenting (CRISP Stent) Study: a prospective, randomized control trial. Circulation 2009; 119(6): 820-7.

[17] Kuzuya T, Hoshida S, Yamashita N, et al. Delayed effects of sublethal ischemia on the acquisition of tolerance to ischemia. Circ Res 1993; 72(6): 1293-9.

[18] Hausenloy DJ, Yellon DM. The second window of preconditioning (SWOP) where are we now? Cardiovasc Drugs Ther 2010; 24(3): 235-54.

[19] Zhao ZQ, Corvera JS, Halkos ME, et al. Inhibition of myocardial injury by ischemic postconditioning during reperfusion: comparison with ischemic preconditioning. Am J Physiol Heart Circ Physiol 2003; 285(2): H579-H588.

[20] Staat P, Rioufol G, Piot C, et al. Postconditioning the human heart. Circulation 2005; 112(14): 2143-8.

[21] Luo W, Li B, Lin G, Huang R. Postconditioning in cardiac surgery for tetralogy of Fallot. J Thorac Cardiovasc Surg 2007; 133(5): 1373-4.

[22] Liu GS, Thornton J, Van Winkle DM, Stanley AW, Olsson RA, Downey JM. Protection against infarction afforded by preconditioning is mediated by $\mathrm{A} 1$ adenosine receptors in rabbit heart. Circulation 1991; 84(1): 350-6.

[23] Parratt JR. Protection of the heart by ischaemic preconditioning: mechanisms and possibilities for pharmacological exploitation. Trends Pharmacol Sci 1994; 15(1): 19-25.

[24] Goto M, Liu Y, Yang XM, Ardell JL, Cohen MV, Downey JM. Role of bradykinin in protection of ischemic preconditioning in rabbit hearts. Circ Res 1995; 77(3): 611-21.

[25] Schultz JE, Rose E, Yao Z, Gross GJ. Evidence for involvement of opioid receptors in ischemic preconditioning in rat hearts. Am J Physiol 1995; 268(5 Pt 2): H2157-H2161.

[26] Yao Z, Gross GJ. Acetylcholine mimics ischemic preconditioning via a glibenclamide-sensitive mechanism in dogs. Am J Physiol 1993; 264(6 Pt 2): H2221-H2225.

[27] Tsuchida A, Liu Y, Liu GS, Cohen MV, Downey JM. alpha 1adrenergic agonists precondition rabbit ischemic myocardium independent of adenosine by direct activation of protein kinase C. Circ Res 1994; 75(3): 576-85.

[28] Liu Y, Tsuchida A, Cohen MV, Downey JM. Pretreatment with angiotensin II activates protein kinase $\mathrm{C}$ and limits myocardial infarction in isolated rabbit hearts. J Mol Cell Cardiol 1995; 27(3): 883-92.

[29] Wang P, Gallagher KP, Downey JM, Cohen MV. Pretreatment with endothelin-1 mimics ischemic preconditioning against infarction in isolated rabbit heart. J Mol Cell Cardiol 1996; 28(3): 579-88.

[30] Ytrehus K, Liu Y, Downey JM. Preconditioning protects ischemic rabbit heart by protein kinase C activation. Am J Physiol 1994; 266(3 Pt 2): H1145-H1152.

[31] Maulik N, Watanabe M, Zu YL, et al. Ischemic preconditioning triggers the activation of MAP kinases and MAPKAP kinase 2 in rat hearts. FEBS Lett 1996; 396(2-3): 233-7.

[32] Sadoshima J, Qiu Z, Morgan JP, Izumo S. Angiotensin II and other hypertrophic stimuli mediated by $G$ protein-coupled receptors activate tyrosine kinase, mitogen-activated protein kinase, and 90kD S6 kinase in cardiac myocytes. The critical role of $\mathrm{Ca}(2+)$ dependent signaling. Circ Res 1995; 76(1): 1-15.

[33] Tong $\mathrm{H}$, Chen W, Steenbergen C, Murphy E. Ischemic preconditioning activates phosphatidylinositol-3-kinase upstream of protein kinase C. Circ Res 2000; 87(4): 309-15.

[34] Hausenloy DJ, Tsang A, Mocanu M, Yellon DM. Ischemic Preconditioning Protects by Activating Pro-Survival Kinases at Reperfusion. Am J Physiol Heart Circ Physiol 2005; 288: H971H976.

[35] Solenkova NV, Solodushko V, Cohen MV, Downey JM. Endogenous adenosine protects preconditioned heart during early minutes of reperfusion by activating Akt. Am J Physiol Heart Circ Physiol 2006; 290(1): H441-H449.

[36] Strohm C, Barancik T, Bruhl ML, Kilian SA, Schaper W. Inhibition of the ER-kinase cascade by PD98059 and UO126 counteracts ischemic preconditioning in pig myocardium. J Cardiovasc Pharmacol 2000; 36(2): 218-29.

[37] Fryer RM, Pratt PF, Hsu AK, Gross GJ. Differential activation of extracellular signal regulated kinase isoforms in preconditioning 
and opioid-induced cardioprotection. J Pharmacol Exp Ther 2001; 296(2): 642-9.

[38] Mocanu MM, Bell RM, Yellon DM. PI3 kinase and not p42/p44 appears to be implicated in the protection conferred by ischemic preconditioning. J Mol Cell Cardiol 2002; 34(6): 661-8.

[39] Saurin AT, Martin JL, Heads RJ, Foley C, Mockridge JW, Wright MJ, Wang Y, Marber MS. The role of differential activation of p38-mitogen-activated protein kinase in preconditioned ventricular myocytes. FASEB J 2000; 14(14): 2237-46.

[40] Behrends M, Schulz R, Post H, Alexandrov A, Belosjorow S, Michel MC, Heusch G. Inconsistent relation of MAPK activation to infarct size reduction by ischemic preconditioning in pigs. Am J Physiol Heart Circ Physiol 2000; 279(3): H1111-H1119.

[41] Takeishi Y, Huang Q, Wang T, et al. Src family kinase and adenosine differentially regulate multiple MAP kinases in ischemic myocardium: modulation of MAP kinases activation by ischemic preconditioning. J Mol Cell Cardiol 2001; 33(11): 1989-2005.

[42] Samavati L, Monick MM, Sanlioglu S, Buettner GR, Oberley LW, Hunninghake GW. Mitochondrial K(ATP) channel openers activate the ERK kinase by an oxidant-dependent mechanism. Am J Physiol Cell Physiol 2002 July; 283(1): C273-C281.

[43] Baines CP, Zhang J, Wang GW, et al. Mitochondrial PKCepsilon and MAPK form signaling modules in the murine heart: enhanced mitochondrial PKCepsilon-MAPK interactions and differential MAPK activation in PKCepsilon-induced cardioprotection. Circ Res 2002; 90(4): 390-7.

[44] Steenbergen C. The role of p38 mitogen-activated protein kinase in myocardial ischemia/reperfusion injury; relationship to ischemic preconditioning. Basic Res Cardiol 2002; 97(4): 276-85.

[45] Ping P, Murphy E. Role of p38 mitogen-activated protein kinases in preconditioning: a detrimental factor or a protective kinase? Circ Res 2000; 86(9): 921-2.

[46] Bogoyevitch MA, Gillespie-Brown J, Ketterman AJ, et al. Stimulation of the stress-activated mitogen-activated protein kinase subfamilies in perfused heart. p38/RK mitogen-activated protein kinases and c-Jun N-terminal kinases are activated by ischemia/reperfusion. Circ Res 1996; 79(2): 162-73.

[47] Weinbrenner C, Liu GS, Cohen MV, Downey JM. Phosphorylation of tyrosine 182 of p38 mitogen-activated protein kinase correlates with the protection of preconditioning in the rabbit heart. J Mol Cell Cardiol 1997; 29(9): 2383-91.

[48] Maulik N, Yoshida T, Zu YL, Sato M, Banerjee A, Das DK. Ischemic preconditioning triggers tyrosine kinase signaling: a potential role for MAPKAP kinase 2. Am J Physiol 1998; 275(5 Pt 2): H1857-H1864.

[49] Mocanu MM, Baxter GF, Yue Y, Critz SD, Yellon DM. The p38 MAPK inhibitor, SB203580, abrogates ischaemic preconditioning in rat heart but timing of administration is critical. Basic Res Cardiol 2000; 95(6): 472-8.

[50] Marais E, Genade S, Huisamen B, Strijdom JG, Moolman JA, Lochner A. Activation of p38 MAPK induced by a multi-cycle ischaemic preconditioning protocol is associated with attenuated p38 MAPK activity during sustained ischaemia and reperfusion. $\mathbf{J}$ Mol Cell Cardiol 2001; 33(4): 769-78.

[51] Gysembergh A, Simkhovich BZ, Kloner RA, Przyklenk K. p38 MAPK activity is not increased early during sustained coronary artery occlusion in preconditioned versus control rabbit heart. J Mol Cell Cardiol 2001; 33(4): 681-90.

[52] Ping P, Zhang J, Huang S, et al. PKC-dependent activation of p46/p54 JNKs during ischemic preconditioning in conscious rabbits. Am J Physiol 1999; 277(5 Pt 2): H1771-H1785.

[53] Sato M, Cordis GA, Maulik N, Das DK. SAPKs regulation of ischemic preconditioning. Am J Physiol Heart Circ Physiol 2000; 279(3): H901-H907.

[54] Lochner A, Marais E, Du TE, Moolman J. Nitric oxide triggers classic ischemic preconditioning. Ann N Y Acad Sci 2002; 962: 402-14.

[55] Sanada S, Kitakaze M, Papst PJ, et al. Role of phasic dynamism of p38 mitogen-activated protein kinase activation in ischemic preconditioning of the canine heart. Circ Res 2001; 88(2): 175-80.

[56] Marais E, Genade S, Salie R, et al. The temporal relationship between p38 MAPK and HSP27 activation in ischaemic and pharmacological preconditioning. Basic Res Cardiol 2005; 100(1): $35-47$.
[57] Nemoto S, Xiang J, Huang S, Lin A. Induction of apoptosis by SB202190 through inhibition of p38beta mitogen-activated protein kinase. J Biol Chem 1998; 273(26): 16415-20.

[58] Schulz R, Gres P, Skyschally A, et al. Ischemic preconditioning preserves connexin 43 phosphorylation during sustained ischemia in pig hearts in vivo. FASEB J 2003; 17(10): 1355-7.

[59] Knight RJ, Buxton DB. Stimulation of c-Jun kinase and mitogenactivated protein kinase by ischemia and reperfusion in the perfused rat heart. Biochem Biophys Res Commun 1996; 218(1): 83-8.

[60] Haq SE, Clerk A, Sugden PH. Activation of mitogen-activated protein kinases (p38-MAPKs, SAPKs/JNKs and ERKs) by adenosine in the perfused rat heart. FEBS Lett 1998; 434(3): 305-8.

[61] Fryer RM, Patel HH, Hsu AK, Gross GJ. Stress-activated protein kinase phosphorylation during cardioprotection in the ischemic myocardium. Am J Physiol Heart Circ Physiol 2001; 281(3): H1184-H1192.

[62] Iliodromitis EK, Gaitanaki C, Lazou A, et al. Dissociation of stress-activated protein kinase (p38-MAPK and JNKs) phosphorylation from the protective effect of preconditioning in vivo. J Mol Cell Cardiol 2002; 34(8): 1019-28.

[63] Nakano A, Baines CP, Kim SO, et al. Ischemic preconditioning activates MAPKAPK2 in the isolated rabbit heart: evidence for involvement of p38 MAPK. Circ Res 2000; 86(2): 144-51.

[64] Kaiser RA, Liang Q, Bueno OF, et al. Genetic inhibition or activation of JNK1/2 each protect the Myocardium from Ischemiareperfusion-induced cell death in vivo. J Biol Chem 2005 July 25

[65] Murry CE, Richard VJ, Reimer KA, Jennings RB. Ischemic preconditioning slows energy metabolism and delays ultrastructural damage during a sustained ischemic episode. Circ Res 1990; 66(4): 913-31.

[66] Kobara M, Tatsumi T, Matoba S, et al. Effect of ischemic preconditioning on mitochondrial oxidative phosphorylation and high energy phosphates in rat hearts. J Mol Cell Cardiol 1996; 28(2): 417-28

[67] Fryer RM, Eells JT, Hsu AK, Henry MM, Gross GJ. Ischemic preconditioning in rats: role of mitochondrial $\mathrm{K}(\mathrm{ATP})$ channel in preservation of mitochondrial function. Am J Physiol Heart Circ Physiol 2000; 278(1): H305-H312.

[68] Iwai T, Tanonaka K, Koshimizu M, Takeo S. Preservation of mitochondrial function by diazoxide during sustained ischaemia in the rat heart. Br J Pharmacol 2000; 129(6): 1219-27.

[69] Dos SP, Kowaltowski AJ, Laclau MN, et al. Mechanisms by which opening the mitochondrial ATP- sensitive $\mathrm{K}(+)$ channel protects the ischemic heart. Am J Physiol Heart Circ Physiol 2002; 283(1): H284-H295.

[70] Kida M, Fujiwara H, Ishida M, et al. Ischemic preconditioning preserves creatine phosphate and intracellular $\mathrm{pH}$. Circulation 1991; 84(6): 2495-503.

[71] Asimakis GK, Inners-McBride K, Medellin G, Conti VR. Ischemic preconditioning attenuates acidosis and postischemic dysfunction in isolated rat heart. Am J Physiol 1992; 263(3 Pt 2): H887-H894.

[72] Steenbergen C, Perlman ME, London RE, Murphy E. Mechanism of preconditioning. Ionic alterations. Circ Res 1993; 72(1): 112-25. Vander Heide RS, Delyani JA, Jennings RB, Reimer KA, Steenbergen C. Reducing lactate accumulation does not attenuate lethal ischemic injury in isolated perfused rat hearts. Am J Physiol 1996; 270(1 Pt 2): H38-H44

[74] Cave AC, Garlick PB. Ischemic preconditioning and intracellular pH: a 31P NMR study in the isolated rat heart. Am J Physiol 1997; 272(1 Pt 2): H544-H552.

[75] Headrick JP. Ischemic preconditioning: bioenergetic and metabolic changes and the role of endogenous adenosine. $\mathrm{J}$ Mol Cell Cardiol 1996; 28(6): 1227-40.

[76] Fujita M, Asanuma H, Hirata A, et al. Prolonged transient acidosis during early reperfusion contributes to the cardioprotective effects of postconditioning. Am J Physiol Heart Circ Physiol 2007 April; 292(4): H2004-H2008.

[77] Cohen MV, Yang XM, Downey JM. The pH hypothesis of postconditioning: staccato reperfusion reintroduces oxygen and perpetuates myocardial acidosis. Circulation 2007; 115(14): 1895903.

[78] Cohen MV, Yang XM, Downey JM. Acidosis, oxygen, and interference with mitochondrial permeability transition pore formation in the early minutes of reperfusion are critical to 
postconditioning's success. Basic Res Cardiol 2008; 103(5): 46471.

[79] Shen AC, Jennings RB. Myocardial calcium and magnesium in acute ischemic injury. Am J Pathol 1972; 67(3): 417-40.

[80] Shen AC, Jennings RB. Kinetics of calcium accumulation in acute myocardial ischemic injury. Am J Pathol 1972; 67(3): 441-52.

[81] Auchampach JA, Gross GJ. Anti-ischaemic actions of potassium channel openers in experimental myocardial ischaemia/reperfusion injury in dogs. Eur Heart J 1993; 14 Suppl B: 10-5.

[82] Holmuhamedov EL, Jovanovic S, Dzeja PP, Jovanovic A, Terzic A. Mitochondrial ATP-sensitive $\mathrm{K}+$ channels modulate cardiac mitochondrial function. Am J Physiol 1998; 275(5 Pt 2): H1567H1576.

[83] Holmuhamedov EL, Wang L, Terzic A. ATP-sensitive K+ channel openers prevent $\mathrm{Ca} 2+$ overload in rat cardiac mitochondria. J Physiol 1999; 519 Pt 2: 347-60.

[84] Wang L, Cherednichenko G, Hernandez L, et al. Preconditioning limits mitochondrial $\mathrm{Ca}(2+)$ during ischemia in rat hearts: role of K(ATP) channels. Am J Physiol Heart Circ Physiol 2001; 280(5): H2321-H2328.

[85] Murata M, Akao M, O'Rourke B, Marban E. Mitochondrial ATPsensitive potassium channels attenuate matrix $\mathrm{Ca}(2+)$ overload during simulated ischemia and reperfusion: possible mechanism of cardioprotection. Circ Res 2001; 89(10): 891-8.

[86] Ishida H, Hirota Y, Genka C, Nakazawa H, Nakaya H, Sato T. Opening of mitochondrial K(ATP) channels attenuates the ouabaininduced calcium overload in mitochondria. Circ Res 2001; 89(10): 856-8.

[87] Riess ML, Camara AK, Novalija E, Chen Q, Rhodes SS, Stowe DF. Anesthetic preconditioning attenuates mitochondrial $\mathrm{Ca} 2+$ overload during ischemia in Guinea pig intact hearts: reversal by 5hydroxydecanoic acid. Anesth Analg 2002; 95(6): 1540-6, table.

[88] Crestanello JA, Doliba NM, Babsky AM, Doliba NM, Niibori K, Whitman GJ, Osbakken MD. Ischemic preconditioning improves mitochondrial tolerance to experimental calcium overload. J Surg Res 2002; 103(2): 243-51.

[89] Crestanello JA, Doliba NM, Babsky AM, et al. Mitochondrial function during ischemic preconditioning. Surgery 2002; 131(2): 172-8.

[90] Crestanello JA, Doliba NM, Babsky AM, Doliba NM, Niibori K, Osbakken MD, Whitman GJ. Opening of potassium channels protects mitochondrial function from calcium overload. J Surg Res 2000; 94(2): 116-23.

[91] Baines CP, Goto M, Downey JM. Oxygen radicals released during ischemic preconditioning contribute to cardioprotection in the rabbit myocardium. J Mol Cell Cardiol 1997; 29(1): 207-16.

[92] Yue Y, Krenz M, Cohen MV, Downey JM, Critz SD. Menadione mimics the infarct-limiting effect of preconditioning in isolated rat hearts. Am J Physiol Heart Circ Physiol 2001; 281(2): H590-H595.

[93] Tosaki A, Cordis GA, Szerdahelyi P, Engelman RM, Das DK. Effects of preconditioning on reperfusion arrhythmias, myocardial functions, formation of free radicals, and ion shifts in isolated ischemic/reperfused rat hearts. J Cardiovasc Pharmacol 1994; 23(3): 365-73.

[94] Crestanello JA, Lingle DM, Kamelgard J, Millili J, Whitman GJ. Ischemic preconditioning decreases oxidative stress during reperfusion: a chemiluminescence study. J Surg Res 1996; 65(1): $53-8$

[95] Vanden Hoek T, Becker LB, Shao ZH, Li CQ, Schumacker PT. Preconditioning in cardiomyocytes protects by attenuating oxidant stress at reperfusion. Circ Res 2000; 86(5): 541-8.

[96] Narayan P, Mentzer RM, Jr., Lasley RD. Adenosine A1 receptor activation reduces reactive oxygen species and attenuates stunning in ventricular myocytes. J Mol Cell Cardiol 2001; 33(1): 121-9.

[97] Ozcan C, Bienengraeber M, Dzeja PP, Terzic A. Potassium channel openers protect cardiac mitochondria by attenuating oxidant stress at reoxygenation. Am J Physiol Heart Circ Physiol 2002; 282(2): H531-H539.

[98] Raphael J, Drenger B, Rivo J, Berenshtein E, Chevion M, Gozal Y. Ischemic preconditioning decreases the reperfusion-related formation of hydroxyl radicals in a rabbit model of regional myocardial ischemia and reperfusion: the role of K(ATP) channels. Free Radic Res 2005; 39(7): 747-54.

[99] Clarke SJ, Khaliulin I, Das M, Parker JE, Heesom KJ, Halestrap AP. Inhibition of mitochondrial permeability transition pore opening by ischemic preconditioning is probably mediated by reduction of oxidative stress rather than mitochondrial protein phosphorylation. Circ Res 2008; 102(9): 1082-90.

[100] Pasdois P, Parker JE, Griffiths EJ, Halestrap AP. The role of oxidized cytochrome $\mathrm{c}$ in regulating mitochondrial reactive oxygen species production and its perturbation in ischaemia. Biochem $\mathrm{J}$ 2011; 436(2): 493-505.

[101] Kevin LG, Camara AK, Riess ML, Novalija E, Stowe DF. Ischemic preconditioning alters real-time measure of $\mathrm{O} 2$ radicals in intact hearts with ischemia and reperfusion. Am J Physiol Heart Circ Physiol 2003; 284(2): H566-H574.

[102] Droge W. Free radicals in the physiological control of cell function. Physiol Rev 2002; 82(1): 47-95.

[103] Murry CE, Richard V, Jennings RB, Reimer KA. Preconditioning with ischemia: is the protective effect mediated by free radicalinduced myocardial stunning? Circulation 78. 1988. Ref Type: Abstract

[104] Tanaka M, Fujiwara H, Yamasaki K, Sasayama S. Superoxide dismutase and N-2-mercaptopropionyl glycine attenuate infarct size limitation effect of ischaemic preconditioning in the rabbit. Cardiovasc Res 1994; 28(7): 980-6.

[105] Chen W, Gabel S, Steenbergen C, Murphy E. A redox-based mechanism for cardioprotection induced by ischemic preconditioning in perfused rat heart. Circ Res 1995; 77(2): 424-9.

[106] Vanden Hoek TL, Becker LB, Shao Z, Li C, Schumacker PT. Reactive oxygen species released from mitochondria during brief hypoxia induce preconditioning in cardiomyocytes. J Biol Chem 1998; 273(29): 18092-8.

[107] Tritto I, D'Andrea D, Eramo N, Scognamiglio A, De Simone C, Violante A, Esposito A, Chiariello M, Ambrosio G. Oxygen radicals can induce preconditioning in rabbit hearts. Circ Res 1997; 80(5): 743-8.

[108] Noma A. ATP-regulated K+ channels in cardiac muscle. Nature 1983; 305(5930): 147-8.

[109] Gross GJ, Auchampach JA. Blockade of ATP-sensitive potassium channels prevents myocardial preconditioning in dogs. Circ Res 1992; 70(2): 223-33.

[110] Auchampach JA, Grover GJ, Gross GJ. Blockade of ischaemic preconditioning in dogs by the novel ATP dependent potassium channel antagonist sodium 5-hydroxydecanoate. Cardiovasc Res 1992; 26(11): 1054-62.

[111] Suzuki M, Saito T, Sato T, Tamagawa M, Miki T, Seino S, Nakaya H. Cardioprotective effect of diazoxide is mediated by activation of sarcolemmal but not mitochondrial ATP-sensitive potassium channels in mice. Circulation 2003; 107(5): 682-5.

[112] Inoue I, Nagase H, Kishi K, Higuti T. ATP-sensitive K+ channel in the mitochondrial inner membrane. Nature 1991; 352(6332): 244-7.

[113] Garlid KD, Paucek P, Yarov-Yarovoy V, et al. Cardioprotective effect of diazoxide and its interaction with mitochondrial ATPsensitive $\mathrm{K}+$ channels. Possible mechanism of cardioprotection. Circ Res 1997; 81(6): 1072-82.

[114] Liu Y, Sato T, O'Rourke B, Marban E. Mitochondrial ATPdependent potassium channels: novel effectors of cardioprotection? Circulation 1998; 97(24): 2463-9.

[115] Pain T, Yang XM, Critz SD, et al. Opening of mitochondrial $\mathrm{K}$ (ATP) channels triggers the preconditioned state by generating free radicals. Circ Res 2000; 87(6): 460-6.

[116] Wang Y, Takashi E, Xu M, Ayub A, Ashraf M. Downregulation of protein kinase $\mathrm{C}$ inhibits activation of mitochondrial $\mathrm{K}(\mathrm{ATP})$ channels by diazoxide. Circulation 2001; 104(1): 85-90.

[117] Forbes RA, Steenbergen C, Murphy E. Diazoxide-induced cardioprotection requires signaling through a redox-sensitive mechanism. Circ Res 2001; 88(8): 802-9.

[118] Krenz M, Oldenburg O, Wimpee H, et al. Opening of ATPsensitive potassium channels causes generation of free radicals in vascular smooth muscle cells. Basic Res Cardiol 2002; 97(5): 36573.

[119] Oldenburg O, Yang XM, Krieg T, et al. P1075 opens mitochondrial $\mathrm{K}(\mathrm{ATP})$ channels and generates reactive oxygen species resulting in cardioprotection of rabbit hearts. J Mol Cell Cardiol 2003; 35(9): $1035-42$.

[120] Jaburek M, Yarov-Yarovoy V, Paucek P, Garlid KD. Statedependent inhibition of the mitochondrial KATP channel by glyburide and 5-hydroxydecanoate. J Biol Chem 1998; 273(22): 13578-82.

[121] Jaburek M, Costa AD, Burton JR, Costa CL, Garlid KD. Mitochondrial PKC \{epsilon $\}$ and Mitochondrial ATP-Sensitive K+ 
Channel Copurify and Coreconstitute to Form a Functioning Signaling Module in Proteoliposomes. Circ Res 2006; 99(8): 87883.

[122] Andrukhiv A, Costa AD, West IC, Garlid KD. Opening mitoKATP increases superoxide generation from complex I of the electron transport chain. Am J Physiol Heart Circ Physiol 2006; 291(5): H2067-H2074.

[123] Hanley PJ, Mickel M, Loffler M, Brandt U, Daut J. K(ATP) channel-independent targets of diazoxide and 5-hydroxydecanoate in the heart. J Physiol 2002; 542(Pt 3): 735-41.

[124] Inagaki N, Gonoi T, Clement JP, et al. A family of sulfonylurea receptors determines the pharmacological properties of ATPsensitive K+ channels. Neuron 1996; 16(5): 1011-7.

[125] Inagaki N, Gonoi T, Clement JP, et al. Reconstitution of IKATP: an inward rectifier subunit plus the sulfonylurea receptor. Science 1995; 270(5239): 1166-70.

[126] Xu W, Liu Y, Wang S, McDonald T, Van Eyk JE, Sidor A, O'Rourke B. Cytoprotective role of Ca2+- activated $\mathrm{K}+$ channels in the cardiac inner mitochondrial membrane. Science 2002; 298(5595): 1029-33.

[127] Ping P, Takano H, Zhang J, et al. Isoform-selective activation of protein kinase $\mathrm{C}$ by nitric oxide in the heart of conscious rabbits: a signaling mechanism for both nitric oxide-induced and ischemiainduced preconditioning. Circ Res 1999; 84(5): 587-604.

[128] Rakhit RD, Edwards RJ, Mockridge JW, et al. Nitric oxide-induced cardioprotection in cultured rat ventricular myocytes. Am J Physiol Heart Circ Physiol 2000; 278(4): H1211-H1217.

[129] Lebuffe G, Schumacker PT, Shao ZH, Anderson T, Iwase H, Vanden Hoek TL. ROS and NO trigger early preconditioning: relationship to mitochondrial KATP channel. Am J Physiol Heart Circ Physiol 2003; 284(1): H299-H308.

[130] Nakano A, Liu GS, Heusch G, Downey JM, Cohen MV. Exogenous nitric oxide can trigger a preconditioned state through a free radical mechanism, but endogenous nitric oxide is not a trigger of classical ischemic preconditioning. J Mol Cell Cardiol 2000; 32(7): 1159-67.

[131] Jones WK, Flaherty MP, Tang XL, et al. Ischemic preconditioning increases iNOS transcript levels in conscious rabbits via a nitric oxide-dependent mechanism. J Mol Cell Cardiol 1999; 31(8): 1469-81.

[132] Guo Y, Stein AB, Wu WJ, et al. Late preconditioning induced by NO donors, adenosine A1 receptor agonists, and delta1-opioid receptor agonists is mediated by iNOS. Am J Physiol Heart Circ Physiol 2005; 289(5): H2251-H2257.

[133] Crompton M, Costi A. Kinetic evidence for a heart mitochondrial pore activated by $\mathrm{Ca} 2+$, inorganic phosphate and oxidative stress. A potential mechanism for mitochondrial dysfunction during cellular Ca2+ overload. Eur J Biochem 1988; 178(2): 489-501.

[134] Crompton M, Ellinger H, Costi A. Inhibition by cyclosporin A of a $\mathrm{Ca} 2+-$ dependent pore in heart mitochondria activated by inorganic phosphate and oxidative stress. Biochem J 1988; 255(1): 357-60.

[135] Baines CP, Kaiser RA, Purcell NH, et al. Loss of cyclophilin D reveals a critical role for mitochondrial permeability transition in cell death. Nature 2005; 434(7033): 658-62.

[136] Nakagawa T, Shimizu S, Watanabe T, et al. Cyclophilin Ddependent mitochondrial permeability transition regulates some necrotic but not apoptotic cell death. Nature 2005; 434(7033): 6528 .

[137] Griffiths EJ, Halestrap AP. Protection by Cyclosporin A of ischemia/reperfusion-induced damage in isolated rat hearts. J Mol Cell Cardiol 1993; 25(12): 1461-9.

[138] Hausenloy DJ, Maddock HL, Baxter GF, Yellon DM. Inhibiting mitochondrial permeability transition pore opening: a new paradigm for myocardial preconditioning? Cardiovasc Res 2002; 55(3): 534-43.

[139] Hausenloy DJ, Duchen MR, Yellon DM. Inhibiting mitochondrial permeability transition pore opening at reperfusion protects against ischaemia-reperfusion injury. Cardiovasc Res 2003; 60(3): 617-25.

[140] Piot C, Croisille P, Staat P, et al. Effect of cyclosporine on reperfusion injury in acute myocardial infarction. $\mathrm{N}$ Engl $\mathrm{J}$ Med 2008; 359(5): 473-81.

[141] Schinzel AC, Takeuchi O, Huang Z, et al. Cyclophilin D is a component of mitochondrial permeability transition and mediates neuronal cell death after focal cerebral ischemia. Proc Natl Acad Sci U S A 2005; 102(34): 12005-10.
[142] Xu M, Wang Y, Hirai K, Ayub A, Ashraf M. Calcium preconditioning inhibits mitochondrial permeability transition and apoptosis. Am J Physiol Heart Circ Physiol 2001; 280(2): H899H908.

[143] Javadov SA, Clarke S, Das M, Griffiths EJ, Lim KH, Halestrap AP. Ischaemic preconditioning inhibits opening of mitochondrial permeability transition pores in the reperfused rat heart. J Physiol 2003; 549(Pt 2): 513-24

[144] Argaud L, Gateau-Roesch O, Chalabreysse L, Gomez L, Loufouat J, Thivolet-Bejui F, Robert D, Ovize M. Preconditioning delays $\mathrm{Ca} 2+$-induced mitochondrial permeability transition. Cardiovasc Res 2004; 61(1): 115-22.

[145] Hausenloy DJ, Yellon DM, Mani-Babu S, Duchen MR. Preconditioning protects by inhibiting the mitochondrial permeability transition. Am J Physiol Heart Circ Physiol 2004; 287(2): H841-H849.

[146] Juhaszova M, Zorov DB, Kim SH, et al. Glycogen synthase kinase3beta mediates convergence of protection signaling to inhibit the mitochondrial permeability transition pore. J Clin Invest 2004; 113(11): 1535-49.

[147] Piriou V, Chiari P, Gateau-Roesch O, et al. Desflurane-induced preconditioning alters calcium-induced mitochondrial permeability transition. Anesthesiology 2004 March; 100(3): 581-8.

[148] Rajesh KG, Sasaguri S, Zhitian Z, Suzuki R, Asakai R, Maeda H. Second window of ischemic preconditioning regulates mitochondrial permeability transition pore by enhancing Bcl-2 expression. Cardiovasc Res 2003; 59(2): 297-307.

[149] Hausenloy DJ, Yellon DM. Adenosine-induced second window of protection is mediated by inhibition of mitochondrial permeability transition pore opening at the time of reperfusion. Cardiovasc Drugs Ther 2004; 18(1): 79-80.

[150] Hausenloy DJ, Ong SB, Yellon DM. The mitochondria permeability transition pore as a target for preconditioning and postconditioning. Basic Res Cardiol 2009; 104(2): 189-202.

[151] Hausenloy D, Wynne A, Duchen M, Yellon D. Transient mitochondrial permeability transition pore opening mediates preconditioning-induced protection. Circulation 2004; 109(14): 1714-7.

[152] Hausenloy DJ, Lim SY, Ong SG, Davidson SM, Yellon DM. Mitochondrial cyclophilin-D as a critical mediator of ischaemic preconditioning. Cardiovasc Res 2010; 88(1): 67-74.

[153] Wang W, Fang H, Groom L, et al. Superoxide flashes in single mitochondria. Cell 2008 July 25; 134(2): 279-90.

[154] Lawson CS, Downey JM. Preconditioning: state of the art myocardial protection. Cardiovasc Res 1993; 27(4): 542-50.

[155] Marber MS, Latchman DS, Walker JM, Yellon DM. Cardiac stress protein elevation 24 hours after brief ischemia or heat stress is associated with resistance to myocardial infarction. Circulation 1993; 88(3): 1264-72.

[156] Baxter GF, Goma FM, Yellon DM. Characterisation of the infarctlimiting effect of delayed preconditioning: timecourse and dosedependency studies in rabbit myocardium. Basic Res Cardiol 1997; 92(3): 159-67.

[157] Currie RW, Karmazyn M, Kloc M, Mailer K. Heat-shock response is associated with enhanced postischemic ventricular recovery. Circ Res 1988; 63(3): 543-9.

[158] McClanahan T, Nao B, Wolke L, Martin BJ, Mezt TE. Brief renal occlusion and reperfusion reduces myocardial infarct size in rabbits. FASEB J 7, A18. 1993. Ref Type: Abstract

[159] Gho BC, Schoemaker RG, van den Doel MA, Duncker DJ, Verdouw PD. Myocardial protection by brief ischemia in noncardiac tissue. Circulation 1996; 94(9): 2193-200.

[160] Przyklenk K, Darling CE, Dickson EW, Whittaker P. Cardioprotection 'outside the box'--the evolving paradigm of remote preconditioning. Basic Res Cardiol 2003; 98(3): 149-57.

[161] Bolte CS, Liao S, Gross GJ, Schultz JJ. Remote preconditioningendocrine factors in organ protection against ischemic injury Endocr Metab Immune Disord Drug Targets 2007; 7(3): 167-75.

[162] Birnbaum Y, Hale SL, Kloner RA. Ischemic preconditioning at a distance: reduction of myocardial infarct size by partial reduction of blood supply combined with rapid stimulation of the gastrocnemius muscle in the rabbit. Circulation 1997; 96(5): 16416.

[163] Kerendi F, Kin H, Halkos ME, et al. Remote postconditioning Brief renal ischemia and reperfusion applied before coronary artery 
reperfusion reduces myocardial infarct size via endogenous activation of adenosine receptors. Basic Res Cardiol 2005 June 17.

[164] Hausenloy DJ, Yellon DM. Preconditioning and postconditioning: united at reperfusion. Pharmacol Ther 2007; 116(2): 173-91.

[165] Dickson EW, Reinhardt CP, Renzi FP, Becker RC, Porcaro WA, Heard SO. Ischemic preconditioning may be transferable via whole blood transfusion: preliminary evidence. J Thromb Thrombolysis 1999; 8(2): 123-9.

[166] Dickson EW, Lorbar M, Porcaro WA, et al. Rabbit heart can be "preconditioned" via transfer of coronary effluent. Am J Physiol 1999; 277(6 Pt 2): H2451-H2457.

[167] Dickson EW, Porcaro WA, Fenton RA, et al. "Preconditioning at a distance" in the isolated rabbit heart. Acad Emerg Med 2000; 7(4): 311-7.

[168] Konstantinov IE, Li J, Cheung MM, et al. Remote ischemic preconditioning of the recipient reduces myocardial ischemiareperfusion injury of the denervated donor heart via a Katp channel-dependent mechanism. Transplantation 2005; 79(12): 1691-5.

[169] Kristiansen SB, Henning O, Kharbanda RK, et al. Remote preconditioning reduces ischemic injury in the explanted heart by a KATP channel-dependent mechanism. Am J Physiol Heart Circ Physiol 2005; 288(3): H1252-H1256.

[170] Pell TJ, Baxter GF, Yellon DM, Drew GM. Renal ischemia preconditions myocardium: role of adenosine receptors and ATPsensitive potassium channels. Am J Physiol 1998; 275(5 Pt 2): H1542-H1547.

[171] Schoemaker RG, van Heijningen CL. Bradykinin mediates cardiac preconditioning at a distance. Am J Physiol Heart Circ Physiol 2000; 278(5): H1571-H1576.

[172] Patel HH, Moore J, Hsu AK, Gross GJ. Cardioprotection at a distance: mesenteric artery occlusion protects the myocardium via an opioid sensitive mechanism. J Mol Cell Cardiol 2002; 34(10): 1317-23.

[173] Tang ZL, Dai W, Li YJ, Deng HW. Involvement of capsaicinsensitive sensory nerves in early and delayed cardioprotection induced by a brief ischaemia of the small intestine. Naunyn Schmiedebergs Arch Pharmacol 1999; 359(3): 243-7.

[174] Hajrasouliha AR, Tavakoli S, Ghasemi M, Jabehdar-Maralani P, Sadeghipour H, Ebrahimi F, Dehpour AR. Endogenous cannabinoids contribute to remote ischemic preconditioning via cannabinoid $\mathrm{CB}(2)$ receptors in the rat heart. Eur J Pharmacol 2007 October 5.

[175] Takaoka A, Nakae I, Mitsunami K, et al. Renal ischemia/reperfusion remotely improves myocardial energy metabolism during myocardial ischemia via adenosine receptors in rabbits: effects of "remote preconditioning". J Am Coll Cardiol 1999; 33(2): 556-64.

[176] Di Filippo C, Rossi F, Rossi S, D'Amico M. Cannabinoid CB2 receptor activation reduces mouse myocardial ischemia-reperfusion injury: involvement of cytokine/chemokines and PMN. J Leukoc Biol 2004; 75(3): 453-9.

[177] Dickson EW, Blehar DJ, Carraway RE, Heard SO, Steinberg G, Przyklenk K. Naloxone blocks transferred preconditioning in isolated rabbit hearts. J Mol Cell Cardiol 2001; 33(9): 1751-6.

[178] Lang SC, Elsasser A, Scheler C, et al. Myocardial preconditioning and remote renal preconditioning--identifying a protective factor using proteomic methods? Basic Res Cardiol 2006; 101(2): 149-58.

[179] Serejo FC, Rodrigues LF, Jr., Silva Tavares KC, de Carvalho AC, Nascimento JH. Cardioprotective properties of humoral factors released from rat hearts subject to ischemic preconditioning. J Cardiovasc Pharmacol 2007; 49(4): 214-20.

[180] Shimizu M, Tropak M, Diaz RJ, et al. Transient limb ischaemia remotely preconditions through a humoral mechanism acting directly on the myocardium: evidence suggesting cross-species protection. Clin Sci (Lond) 2009; 117(5): 191-200.

[181] Breivik L, Helgeland E, Aarnes EK, Mrdalj J, Jonassen AK. Remote postconditioning by humoral factors in effluent from ischemic preconditioned rat hearts is mediated via PI3K/Aktdependent cell-survival signaling at reperfusion. Basic Res Cardiol 2011; 106(1): 135-45.

[182] Ding YF, Zhang MM, He RR. Role of renal nerve in cardioprotection provided by renal ischemic preconditioning in anesthetized rabbits. Sheng Li Xue Bao 2001; 53(1): 7-12.
[183] Liem DA, Verdouw PD, Ploeg H, Kazim S, Duncker DJ. Sites of action of adenosine in interorgan preconditioning of the heart. Am J Physiol Heart Circ Physiol 2002; 283(1): H29-H37.

[184] Wolfrum S, Schneider K, Heidbreder M, Nienstedt J, Dominiak P, Dendorfer A. Remote preconditioning protects the heart by activating myocardial PKCepsilon-isoform. Cardiovasc Res 2002; 55(3): 583-9.

[185] Li YJ, Xiao ZS, Peng CF, Deng HW. Calcitonin gene-related peptide-induced preconditioning protects against ischemiareperfusion injury in isolated rat hearts. Eur J Pharmacol 1996 September $12 ; 311(2-3)$ : 163-7.

[186] Xiao L, Lu R, Hu CP, Deng HW, Li YJ. Delayed cardioprotection by intestinal preconditioning is mediated by calcitonin gene-related peptide. Eur J Pharmacol 2001; 427(2): 131-5.

[187] Wolfrum S, Nienstedt J, Heidbreder M, Schneider K, Dominiak P, Dendorfer A. Calcitonin gene related peptide mediates cardioprotection by remote preconditioning. Regul Pept 2005; 127(1-3): 217-24.

[188] Konstantinov IE, Arab S, Kharbanda RK, et al. The remote ischemic preconditioning stimulus modifies inflammatory gene expression in humans. Physiol Genomics 2004; 19(1): 143-50.

[189] Konstantinov IE, Arab S, Li J, et al. The remote ischemic preconditioning stimulus modifies gene expression in mouse myocardium. J Thorac Cardiovasc Surg 2005; 130(5): 1326-32.

[190] Peralta C, Fernandez L, Panes J, et al. Preconditioning protects against systemic disorders associated with hepatic ischemiareperfusion through blockade of tumor necrosis factor-induced $\mathrm{P}$ selectin up-regulation in the rat. Hepatology 2001; 33(1): 100-13.

[191] Vinten-Johansen J. Postconditioning: a mechanical maneuver that triggers biological and molecular cardioprotective responses to reperfusion. Heart Fail Rev 2007; 12(3-4): 235-44.

[192] Singh D, Chopra K. Evidence of the role of angiotensin AT(1) receptors in remote renal preconditioning of myocardium. Methods Find Exp Clin Pharmacol 2004; 26(2): 117-22.

[193] Weinbrenner C, Nelles M, Herzog N, Sarvary L, Strasser RH. Remote preconditioning by infrarenal occlusion of the aorta protects the heart from infarction: a newly identified non-neuronal but PKC-dependent pathway. Cardiovasc Res 2002; 55(3): 590601.

[194] Ren X, Wang Y, Jones WK. TNF-alpha is required for late ischemic preconditioning but not for remote preconditioning of trauma. J Surg Res 2004; 121(1): 120-9.

[195] Jones WK, Fan GC, Liao S, et al. Peripheral nociception associated with surgical incision elicits remote nonischemic cardioprotection via neurogenic activation of protein kinase $\mathrm{C}$ signaling. Circulation 2009; 120(11 Suppl): S1-S9.

[196] Gross GJ, Baker JE, Moore J, Falck JR, Nithipatikom K. Abdominal Surgical Incision Induces Remote Preconditioning of Trauma (RPCT) via Activation of Bradykinin Receptors (BK2R) and the Cytochrome P450 Epoxygenase Pathway in Canine Hearts. Cardiovasc Drugs Ther 2011 July 26.

[197] Wei M, Xin P, Li S, et al. Repeated remote ischemic postconditioning protects against adverse left ventricular remodeling and improves survival in a rat model of myocardial infarction. Circ Res 2011; 108(10): 1220-5.

[198] Na HS, Kim YI, Yoon YW,. Ventricular premature beat-driven intermittent restoration of coronary blood flow reduces the incidence of reperfusion-induced ventricular fibrillation in a cat model of regional ischemia. Am Heart J 1996; 132(1 Pt 1): 78-83.

[199] Okamoto F, Allen BS, Buckberg GD, Bugyi H, Leaf J. Reperfusion conditions: importance of ensuring gentle versus sudden reperfusion during relief of coronary occlusion. $\mathbf{J}$ Thorac Cardiovasc Surg 1986; 92 (3 Pt 2): 613-20.

[200] Sato H, Jordan JE, Zhao ZQ, Sarvotham SS, Vinten-Johansen J. Gradual reperfusion reduces infarct size and endothelial injury but augments neutrophil accumulation. Ann Thorac Surg 1997; 64(4): 1099-107.

[201] Skyschally A, van Caster P, Iliodromitis EK, Schulz R, Kremastinos DT, Heusch G. Ischemic postconditioning: experimental models and protocol algorithms. Basic Res Cardiol 2009; 104(5): 469-83.

[202] Hausenloy DJ. Signalling pathways in ischaemic postconditioning. Thromb Haemost 2009; 101(4): 626-34

[203] Yang XM, Philipp S, Downey JM, Cohen MV. Postconditioning's protection is not dependent on circulating blood factors or cells but 
involves adenosine receptors and requires PI3-kinase and guanylyl cyclase activation. Basic Res Cardiol 2005; 100(1): 57-63.

[204] Xi L, Das A, Zhao ZQ, Merino VF, Bader M, Kukreja RC. Loss of myocardial ischemic postconditioning in adenosine $\mathrm{A} 1$ and bradykinin B2 receptors gene knockout mice. Circulation 2008; 118(14 Suppl): S32-S37.

[205] Kin H, Zatta AJ, Lofye MT, Amerson BS, Halkos ME, Kerendi F, Zhao ZQ, Guyton RA, Headrick JP, Vinten-Johansen J. Postconditioning reduces infarct size via adenosine receptor activation by endogenous adenosine. Cardiovasc Res 2005; 67(1): 124-33.

[206] Philipp S, Yang XM, Cui L, Davis AM, Downey JM, Cohen MV. Postconditioning protects rabbit hearts through a protein kinase Cadenosine A2b receptor cascade. Cardiovasc Res 2006; 70(2): 30814.

[207] Penna C, Mancardi D, Rastaldo R, Losano G, Pagliaro P. Intermittent activation of bradykinin $\mathrm{B}(2)$ receptors and mitochondrial K(ATP) channels trigger cardiac postconditioning through redox signaling. Cardiovasc Res 2007 March 12.

[208] Zatta AJ, Kin H, Yoshishige D, et al. Evidence that cardioprotection by postconditioning involves preservation of myocardial opioid content and selective opioid receptor activation. Am J Physiol Heart Circ Physiol 2008 March; 294(3): H1444H1451.

[209] Jiang R, Deneve J, Eldaif S, Wang N-P, Zhao Z-Q, VintenJohansen J. In vivo cardioprotection by postconditioning is mediated by endogenous PAR2 activation. Circulation 116. 2007.

[210] Burley DS, Baxter GF. B-type natriuretic peptide at early reperfusion limits infarct size in the rat isolated heart. Basic Res Cardiol 2007; 102(6): 529-41.

[211] Hausenloy DJ, Yellon DM. New directions for protecting the heart against ischaemia-reperfusion injury: targeting the Reperfusion Injury Salvage Kinase (RISK)-pathway. Cardiovasc Res 2004; 61(3): 448-60

[212] Hausenloy DJ, Yellon DM. Reperfusion injury salvage kinase signalling: taking a RISK for cardioprotection. Heart Fail Rev 2007; 12(3-4): 217-34.

[213] Tsang A, Hausenloy DJ, Mocanu MM, Yellon DM. Postconditioning: a form of "modified reperfusion" protects the myocardium by activating the phosphatidylinositol 3-kinase-Akt pathway. Circ Res 2004; 95(3): 230-2.

[214] Yang XM, Proctor JB, Cui L, Krieg T, Downey JM, Cohen MV. Multiple, brief coronary occlusions during early reperfusion protect rabbit hearts by targeting cell signaling pathways. J Am Coll Cardiol 2004; 44(5): 1103-10.

[215] Zhu M, Feng J, Lucchinetti E, Fischer G, Xu L, Pedrazzini T, Schaub MC, Zaugg M. Ischemic postconditioning protects remodeled myocardium via the PI3K-PKB/Akt reperfusion injury salvage kinase pathway. Cardiovasc Res 2006; 72(1): 152-62.

[216] Feng J, Fischer G, Lucchinetti E, Zhu M, Bestmann L, Jegger D, Arras M, Pasch T, Perriard JC, Schaub MC, Zaugg M. Infarctremodeled myocardium is receptive to protection by isoflurane postconditioning: role of protein kinase B/Akt signaling. Anesthesiology 2006; 104(5): 1004-14.

[217] Sivaraman V, Mudalgiri NR, Di Salvo C, et al. Postconditioning protects human atrial muscle through the activation of the RISK pathway. Basic Res Cardiol 2007; 102(5): 453-9.

[218] Bouhidel O, Pons S, Souktani R, Zini R, Berdeaux A, Ghaleh B. Myocardial ischemic postconditioning against ischemia-reperfusion is impaired in ob/ob mice. Am J Physiol Heart Circ Physiol 2008; 295(4): H1580-H1586.

[219] Boengler K, Buechert A, Heinen Y, et al. Cardioprotection by ischemic postconditioning is lost in aged and STAT3-deficient mice. Circ Res 2008; 102(1): 131-5.

[220] Goodman MD, Koch SE, Fuller-Bicer GA, Butler KL. Regulating RISK: a role for JAK-STAT signaling in postconditioning? Am J Physiol Heart Circ Physiol 2008; 295(4): H1649-H1656.

[221] Boengler K, Hilfiker-Kleiner D, Drexler H, Heusch G, Schulz R. The myocardial JAK/STAT pathway: From protection to failure. Pharmacol Ther 2008; 120(2): 172-85.

[222] Vessey DA, Kelley M, Li L, et al. Role of sphingosine kinase activity in protection of heart against ischemia reperfusion injury. Med Sci Monit 2006; 12(10): BR318-BR324.

[223] Jin ZQ, Karliner JS, Vessey DA. Ischaemic postconditioning protects isolated mouse hearts against ischaemia/reperfusion injury via sphingosine kinase isoform-1 activation. Cardiovasc Res 2008; 79(1): 134-40.

[224] Yellon DM, Downey JM. Preconditioning the myocardium: from cellular physiology to clinical cardiology. Physiol Rev 2003; 83(4): 1113-51.

[225] Penna C, Rastaldo R, Mancardi D, et al. Post-conditioning induced cardioprotection requires signaling through a redox-sensitive mechanism, mitochondrial ATP-sensitive $\mathrm{K}+$ channel and protein kinase C activation. Basic Res Cardiol 2006; 101(2): 180-9.

[226] Zatta AJ, Kin H, Lee G, et al. Infarct-sparing effect of myocardial postconditioning is dependent on protein kinase $\mathrm{C}$ signalling. Cardiovasc Res 2006 May 1; 70(2): 315-24.

[227] Kuno A, Solenkova NV, Solodushko V, et al. Infarct limitation by a protein kinase $\mathrm{G}$ activator at reperfusion in rabbit hearts is dependent on sensitizing the heart to $\mathrm{A} 2 \mathrm{~b}$ agonists by protein kinase C. Am J Physiol Heart Circ Physiol 2008; 295(3): H1288H1295.

[228] Burley DS, Ferdinandy P, Baxter GF. Cyclic GMP and protein kinase-G in myocardial ischaemia-reperfusion: opportunities and obstacles for survival signaling. Br J Pharmacol 2007; 152(6): 85569.

[229] Costa AD, Garlid KD, West IC, Lincoln TM, Downey JM, Cohen MV, Critz SD. Protein kinase G transmits the cardioprotective signal from cytosol to mitochondria. Circ Res 2005; 97(4): 329-36.

[230] Penna C, Cappello S, Mancardi D, et al. Post-conditioning reduces infarct size in the isolated rat heart: role of coronary flow and pressure and the nitric oxide/cGMP pathway. Basic Res Cardiol 2006; 101(2): 168-79.

[231] Costa AD, Garlid KD, West IC, et al. Protein kinase G transmits the cardioprotective signal from cytosol to mitochondria. Circ Res 2005; 97(4): 329-36.

[232] Costa AD, Jakob R, Costa CL, Andrukhiv K, West IC, Garlid KD. The mechanism by which the mitochondrial ATP-sensitive K+ channel opening and $\mathrm{H} 2 \mathrm{O} 2$ inhibit the mitochondrial permeability transition. J Biol Chem 2006; 281(30): 20801-8.

[233] Hausenloy DJ, Yellon DM. The mitochondrial permeability transition pore: its fundamental role in mediating cell death during ischaemia and reperfusion. J Mol Cell Cardiol 2003; 35(4): 339-41.

[234] Leung AW, Halestrap AP. Recent progress in elucidating the molecular mechanism of the mitochondrial permeability transition pore. Biochim Biophys Acta 2008; 1777(7-8): 946-52.

[235] Lim SY, Davidson SM, Hausenloy DJ, Yellon DM. Preconditioning and postconditioning: the essential role of the mitochondrial permeability transition pore. Cardiovasc Res 2007; 75(3): 530-5.

[236] Argaud L, Gateau-Roesch O, Raisky O, Loufouat J, Robert D, Ovize M. Postconditioning inhibits mitochondrial permeability transition. Circulation 2005; 111(2): 194-7.

[237] Bopassa JC, Ferrera R, Gateau-Roesch O, Couture-Lepetit E, Ovize M. PI 3-kinase regulates the mitochondrial transition pore in controlled reperfusion and postconditioning. Cardiovasc Res 2006; 69(1): 178-85.

[238] Davidson SM, Hausenloy D, Duchen MR, Yellon DM. Signalling via the reperfusion injury signalling kinase (RISK) pathway links closure of the mitochondrial permeability transition pore to cardioprotection. Int J Biochem Cell Biol 2006; 38(3): 414-9.

[239] Inserte J, Barba I, Hernando V, Garcia-Dorado D. Delayed recovery of intracellular acidosis during reperfusion prevents calpain activation and determines protection in postconditioned myocardium. Cardiovasc Res 2008 October 15.

[240] Snabaitis AK, Cuello F, Avkiran M. Protein kinase B/Akt phosphorylates and inhibits the cardiac $\mathrm{Na}+\mathrm{H}+$ exchanger NHE1. Circ Res 2008; 103(8): 881-90.

[241] Donato M, D'Annunzio V, Berg G, et al. Ischemic postconditioning reduces infarct size by activation of $\mathrm{A} 1$ receptors and $\mathrm{K}+(\mathrm{ATP})$ channels in both normal and hypercholesterolemic rabbits. J Cardiovasc Pharmacol 2007; 49(5): 287-92.

[242] Mykytenko J, Reeves JG, Kin H, et al. Persistent beneficial effect of postconditioning against infarct size: role of mitochondrial K(ATP) channels during reperfusion. Basic Res Cardiol 2008; 103(5): 472-84.

[243] Downey JM, Cohen MV. A really radical observation--a comment on Penna et al. in Basic Res Cardiol (2006) 101: 180-189. Basic Res Cardiol 2006; 101(2): 190-1.

[244] Tsutsumi YM, Yokoyama T, Horikawa Y, Roth DM, Patel HH. Reactive oxygen species trigger ischemic and pharmacological 
postconditioning: in vivo and in vitro characterization. Life Sci 2007; 81(15): 1223-7.

[245] Yang XM, Downey JM, Cohen MV. Multiple brief coronary occlusions during early reperfusion protect rabbit hearts by activation of Erk and production of nitric oxide. Circulation 108[Abstract 745]. 2003.

[246] Halkos ME, Kerendi F, Corvera JS, et al. Myocardial protection with postconditioning is not enhanced by ischemic preconditioning. Ann Thorac Surg 2004; 78(3): 961-9.

[247] Xin $\mathrm{P}$, Zhu W, Li J, et al. Combined local ischemic postconditioning and remote perconditioning recapitulate cardioprotective effects of local ischemic preconditioning. Am J Physiol Heart Circ Physiol 2010; 298(6): H1819-H1831.

[248] Li Q, Guo Y, Xuan YT, et al. Gene therapy with inducible nitric oxide synthase protects against myocardial infarction via a cyclooxygenase-2-dependent mechanism. Circ Res 2003; 92(7): 741-8.

[249] Li Q, Bolli R, Qiu Y, Tang XL, Murphree SS, French BA. Gene therapy with extracellular superoxide dismutase attenuates myocardial stunning in conscious rabbits. Circulation 1998; 98(14): 1438-48.

[250] Li Q, Bolli R, Qiu Y, Tang XL, Guo Y, French BA. Gene therapy with extracellular superoxide dismutase protects conscious rabbits against myocardial infarction. Circulation 2001; 103(14): 1893-8.

[251] Bolli R, Li QH, Tang XL, Guo Y, Xuan YT, Rokosh G, Dawn B. The late phase of preconditioning and its natural clinical application--gene therapy. Heart Fail Rev 2007; 12(3-4): 189-99.

[252] Li Q, Guo Y, Ou Q, et al. Gene transfer as a strategy to achieve permanent cardioprotection II: rAAV-mediated gene therapy with heme oxygenase-1 limits infarct size 1 year later without adverse functional consequences. Basic Res Cardiol 2011 July 22.

[253] Li Q, Guo Y, Wu WJ, et al. Gene transfer as a strategy to achieve permanent cardioprotection I: rAAV-mediated gene therapy with inducible nitric oxide synthase limits infarct size 1 year later without adverse functional consequences. Basic Res Cardiol 2011 July 21.

[254] Haider HK, Ashraf M. Strategies to promote donor cell survival: combining preconditioning approach with stem cell transplantation. J Mol Cell Cardiol 2008; 45(4): 554-66.

[255] Ii M, Nishimura H, Iwakura A, Wecker A, Eaton E, Asahara T, Losordo DW. Endothelial progenitor cells are rapidly recruited to myocardium and mediate protective effect of ischemic preconditioning via "imported" nitric oxide synthase activity. Circulation 2005; 111(9): 1114-20.

[256] Kimura M, Ueda K, Goto C, et al. Repetition of ischemic preconditioning augments endothelium-dependent vasodilation in humans: role of endothelium-derived nitric oxide and endothelial progenitor cells. Arterioscler Thromb Vasc Biol 2007; 27(6): 1403 10 .

[257] Kamota T, Li TS, Morikage N, et al. Ischemic pre-conditioning enhances the mobilization and recruitment of bone marrow stem cells to protect against ischemia/reperfusion injury in the late phase. J Am Coll Cardiol 2009; 53(19): 1814-22.

[258] Kudej RK, Shen YT, Peppas AP, et al. Obligatory role of cardiac nerves and alpha1-adrenergic receptors for the second window of ischemic preconditioning in conscious pigs. Circ Res 2006; 99(11): 1270-6.

[259] Latronico MV, Condorelli G. MicroRNAs and cardiac pathology. Nat Rev Cardiol 2009; 6(6): 419-29.

[260] Salloum FN, Yin C, Kukreja RC. Role of microRNAs in cardiac preconditioning. J Cardiovasc Pharmacol 2010; 56(6): 581-8.

[261] Yin C, Wang X, Kukreja RC. Endogenous microRNAs induced by heat-shock reduce myocardial infarction following ischemiareperfusion in mice. FEBS Lett 2008; 582(30): 4137-42.

[262] Yin C, Salloum FN, Kukreja RC. A novel role of microRNA in late preconditioning: upregulation of endothelial nitric oxide synthase and heat shock protein 70. Circ Res 2009; 104(5): 572-5. 